\title{
On the role of laser-induced microstructures in influencing the surface energy of magnesia partially stabilized zirconia bioceramic
}

L Hao* and J Lawrence

Manufacturing Engineering Division, School of Mechanical and Production Engineering, Nanyang Technological University, Singapore

\begin{abstract}
Surface energy must in some way be connected to surface chemistry and is therefore an important determinant of a biomaterial's functions. This work elucidates the basic phenomena and wetting mechanisms associated for a widely used bioinert ceramic, magnesia partially stabilized zirconia (MgO-PSZ) following $\mathrm{CO}_{2}$ laser treatment. Contact angles for a set of test liquids were used to measure the wettability characteristics and to reduce the surface energy of the MgO-PSZ before and after $\mathrm{CO}_{2}$ laser treatment. $\mathrm{CO}_{2}$ laser treatment of the MgO-PSZ surface was seen to effect an improvement in the material's wettability characteristics. Furthermore, it was found that the extent of wettability modification was closely related to the microstructure induced by $\mathrm{CO}_{2}$ laser radiation on the surface of the MgO-PSZ.
\end{abstract}

Keywords: $\mathrm{CO}_{2}$ laser, magnesia partially stabilized zirconia (MgO-PSZ), surface energy, microstructure, wettability characteristics

\section{NOTATION}

$D_{\mathrm{R}}$

$F_{\mathrm{R}}$

$G$

$r$

$R$

$W_{\text {ad }}$

$W_{\mathrm{ad}}^{\mathrm{d}}$

$W_{\mathrm{ad}}^{\mathrm{p}}$

$\gamma^{\mathrm{d}}$

$\gamma^{\mathrm{d}}$

$\gamma^{\mathrm{p}}$

$\gamma_{\text {lv }}$

$\gamma_{1 \mathrm{v}}^{\mathrm{d}}$

$\gamma_{1 \mathrm{v}}^{\mathrm{p}}$
Wenzel-type roughness

interfacial free energy of adhesion

thermal gradient $(\mathrm{K} / \mathrm{cm})$

roughness factor

solidification rate $(\mathrm{cm} / \mathrm{s})$

work of adhesion $(\mathrm{J})$

dispersive component of work of adhesion $(\mathrm{J})$

polar component of work of adhesion $(\mathrm{J})$

surface energy $\left(\mathrm{mJ} / \mathrm{m}^{2}\right)$

dispersive component of the surface energy $\left(\mathrm{mJ} / \mathrm{m}^{2}\right)$

polar component of the surface energy $\left(\mathrm{mJ} / \mathrm{m}^{2}\right)$

liquid-vapour surface energy $\left(\mathrm{mJ} / \mathrm{m}^{2}\right)$

dispersive component of the liquid-vapour

surface energy $\left(\mathrm{mJ} / \mathrm{m}^{2}\right)$

polar component of the liquid-vapour surface energy $\left(\mathrm{mJ} / \mathrm{m}^{2}\right)$
The MS was received on 28 February 2003 and was accepted after revision for publication on 9 October 2003.

* Corresponding author: Materials Laboratory N3.1-B2b-02, School of Mechanical and Production Engineering, Nanyang Technological University, 50 Nanyang Avenue, Singapore 639798. $\gamma_{\mathrm{sl}} \quad$ solid-vapour surface energy $\left(\mathrm{mJ} / \mathrm{m}^{2}\right)$

$\gamma_{\mathrm{sv}} \quad$ solid-vapour surface energy $\left(\mathrm{mJ} / \mathrm{m}^{2}\right)$

$\gamma_{\mathrm{sv}}^{\mathrm{d}} \quad$ dispersive component of the solid-vapour

surface energy $\left(\mathrm{mJ} / \mathrm{m}^{2}\right)$

$\gamma_{\mathrm{sv}}^{\mathrm{p}} \quad$ polar component of the solid-vapour surface energy $\left(\mathrm{mJ} / \mathrm{m}^{2}\right)$

$\theta \quad$ contact angle $(\mathrm{deg})$

$\theta_{\text {ideal }}$ contact angle for an ideal smooth surface

$\theta_{\text {rad }}$ radial contact angle

$\theta_{\text {rough }}$ contact angle for a rough surface

$\theta_{\mathrm{th}} \quad$ theoretical contact angle

\section{INTRODUCTION}

The biocompatibility of a material is determined by the interactions between the implant and biological system on the micrometre and nanometre scales [1], and the physicochemical surface properties of the materials. For example, the chemical composition, surface energy, semiconductor properties and surface charge play important roles. Laser surface processing has proven to be a controllable and flexible technique for modifying the surface properties of biomaterials, e.g. laser treatments such as patterning and microfabrication $[2,3]$, pulsedlaser deposition of biocompatible ceramics [4-8], improving the surface corrosion of biometals [9-11] and 
laser treatment of plasma sprayed hydroxyapatite coating [12].

Surface energy should be in some way connected to surface chemistry; consequently, it is an important determinant of biomaterials functions. In previous work concerned with biomaterials, a $\mathrm{CO}_{2}$ pulsed laser was used to graft a biopolymer [13] and a biorubber [14] for the purpose of improved surface hydrophilicity, and to cause the change in the wettability of a polyethylene terephthalate (PET) surface. Moreover, Lawrence and $\mathrm{Li}\left[\mathbf{1 5}\right.$ ] compared the effects of a $\mathrm{CO}_{2}$ laser, a $\mathrm{Nd}$ doped yttrium aluminium garnet (Nd:YAG) laser, an excimer laser and a high-power diode laser (HPDL) on the wettability characteristics of polymethyl methacrylate (PMMA), a biopolymer, and found that the various laser beams caused different changes in the wetttability characteristics. In addition, there have been many investigations into the application of laser radiation to alter the wettability characteristics of many materials. Lawrence and $\mathrm{Li}$ showed that laser surface processing affected the surface energy of metals $[\mathbf{1 6}, \mathbf{1 7}]$. Likewise, much work showed that excimer radiation affected the wettability characteristics of PET [18-20], polyparaphenylene terethalamide (PPTA) [21] and polyether-etherketone (PEEK) $[\mathbf{2 2}, 23]$ and enhanced the coating adhesion of metals $[\mathbf{2 4}, \mathbf{2 5}]$. The existing work is concerned predominantly with polymers and metals, and no work has hitherto been conducted on the laser processing of the bioinert ceramics.

However, it is recognized in the small amount of pertinent literature that the use of laser radiation for the modifying the wettability characteristics of engineering ceramics materials is feasible. Lawrence and $\mathrm{Li}$ [26] have shown that the texturing of ceramics (with an excimer laser at $248 \mathrm{~nm}$ ) can enhance the adhesion strength. Moreover, Lawrence and co-workers found that HPDL treatment of the $\mathrm{SiO}_{2}-\mathrm{Al}_{2} \mathrm{O}_{3}$ basic ceramic (ceramic tile) [26], the $\mathrm{SiO}_{2}-\mathrm{Al}_{2} \mathrm{O}_{3}-\mathrm{Fe}_{2} \mathrm{O}_{3}$-based ceramic (clay quarry tile) and $\mathrm{Al}_{2} \mathrm{O}_{3}$ and $\mathrm{SiO}_{2}-\mathrm{TiO}_{2}$ [27] resulted in an improvement in the wettability characteristics. The alterations in the surface roughness, the surface $\mathrm{O}$ content and polar component of surface energy were found to be the mechanisms active in modification of wettability. Further study [28] showed that the surface energy is the most predominant factor governing the wetting characteristics of the $\mathrm{SiO}_{2}-\mathrm{Al}_{2} \mathrm{O}_{3}$-based ceramic. In work, Hao and Lawrence [29] proved the ability of laser surface treatment to modify the wettability characteristics of the magnesia partially stabilized zirconia (MgO-PSZ) and thereby achieved a favourable cell attachment on the modified MgO-PSZ [30].

This work investigates the basic phenomena and wetting mechanisms associated with $\mathrm{CO}_{2}$ laser processing of $\mathrm{MgO}$-PSZ, the widely used bioinert ceramic with high mechanical strength and excellent corrosion resistance. Contact angles of a set of liquids are used to measure the wettability characteristics and to calculate the surface energy of the MgO-PSZ before and after $\mathrm{CO}_{2}$ laser surface treatment. The relationship between the $\mathrm{CO}_{2}$ laser-induced microstructures and wettability characteristics of the MgO-PSZ was analysed.

\section{EXPERIMENTAL PROCEDURES}

\subsection{Material specifications}

The material under investigation was a 4 per cent $\mathrm{MgO}$ PSZ. The material was obtained in sheet form with dimensions $50 \mathrm{~mm} \times 50 \mathrm{~mm} \times 2.15 \mathrm{~mm} \quad$ (Goodfellow Limited) but, for experimental convenience, it was cut into blocks of $50 \mathrm{~mm} \times 12 \mathrm{~mm} \times 2.15 \mathrm{~mm}$ with a diamond blade cutter. The material was used as received prior to laser treatment.

\subsection{Laser experimental arrangement}

A $3 \mathrm{~kW} \mathrm{CO}$ laser emitting with a wavelength of $10.6 \mu \mathrm{m}$ was used in this study. The laser produced a transverse electromagnetic mode $\left(\mathrm{TEM}_{01}\right)$ beam and was operated in the continuous-wave mode. Figure 1 illustrates the full arrangement complete with the five-axis workstation (Trumpf, Limited). As can be seen, a series of optical units are used to deliver the $\mathrm{CO}_{2}$ laser unit to the stage through the laser head, which is positioned by means of two linear axes ( $y$ and $z$ axes) and two rotary axes ( $b$ and $c$ axes). The defocused $\mathrm{CO}_{2}$ laser beam was fired and traversed across the surface of the MgO-PSZ samples placed on the stage using the $x$ axis. The defocused laser beam with $11 \mathrm{~mm}$ spot diameter was passed over the surface of the specimen single time. The fumes produced were removed with an extraction system, while $\mathrm{O}_{2}$ process gas at a pressure of 2 bar was used to shield the laser optics and to assist the surface treatment.

\subsection{Wettability characteristics analysis procedure}

To investigate the effects of laser radiation on the wetting and surface energy characteristics of the MgO-PSZ, a set of sessile drop control experiments were carried out using glycerol, formamide, ethane glycol, polyglycol E-200 and polyglycol 15-200. The test liquids, together with their total surface energies $\gamma_{\mathrm{lv}}$, dispersive component values $\gamma_{\mathrm{lv}}^{\mathrm{d}}$ and polar component values $\gamma_{\mathrm{lv}}^{\mathrm{p}}[\mathbf{3 1}]$ are detailed in Table 1.

The contact angles of the test liquids on the untreated and $\mathrm{CO}_{2}$-laser-treated $\mathrm{MgO}$-PSZ were determined in atmospheric conditions at $25^{\circ} \mathrm{C}$ using a sessile drop measure machine (Fist Ten Ångstroms, Inc.). In order to estimate the influence of contaminant layers on the measurement results, the specimens of the untreated $\mathrm{MgO}-\mathrm{PSZ}$ were cleaned with acetone in an ultrasonic 


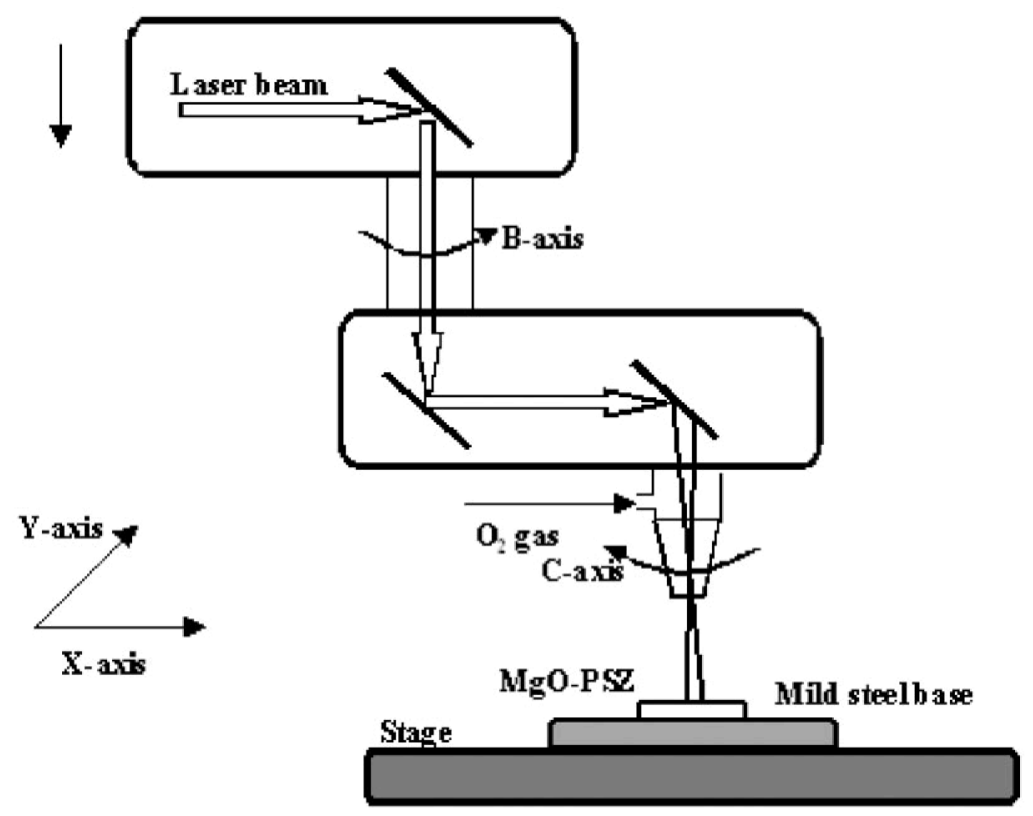

Fig. 1 Schematic diagram of the experimental set-up for the $\mathrm{CO}_{2}$ laser surface treatment of the MgO-PSZ

bath for $2 \mathrm{~h}$, rinsed with distilled water several times and dried in a vacuum oven at $90^{\circ} \mathrm{C}$ for $12 \mathrm{~h}$. The test liquids were used to measure the contact angle for the cleaned sample. It was observed that the value of the contact angles on the cleaned sample are 1.5, 1.2, 1.0, 0.9 and $0.8^{\circ}$ for glycerol, formamide, ethane glycol, polyglycol E-200 and polyglycol 15-200 respectively, lower than that of the received sample without the cleaning. It is assumed that the contaminant on the surface of the $\mathrm{MgO}-\mathrm{PSZ}$ has only a slight influence on the value of contact angle. Since the contaminant is a minor factor active in the wettability characterization, it is reasonable to omit cleaning pre-treatment for practical application of laser treatment. In order to explore the potential of laser treatment as an industrial and economical processing for altering the wettability of $\mathrm{MgO}-\mathrm{PSZ}$, the current research is conducted on atmospheric environment without pre-cleaning. The results on the contact angle were obtained using the average values of five measurements for one sample that were measured immediately after laser treatment. Each measurement of contact angle lasted for $3 \mathrm{~min}$ with

Table 1 Total surface energies $\gamma_{\mathrm{lv}}$ and their dispersive components $\gamma_{\mathrm{lv}}^{\mathrm{d}}$ and polar components $\gamma_{\mathrm{lv}}^{\mathrm{p}}$ for the selected test liquids [30]

\begin{tabular}{llll}
\hline Liquid & $\begin{array}{l}\gamma_{\mathrm{lv}} \\
\left(\mathrm{mJ} / \mathrm{m}^{2}\right)\end{array}$ & $\begin{array}{l}\gamma_{\mathrm{lv}}^{\mathrm{d}} \\
\left(\mathrm{mJ} / \mathrm{m}^{2}\right)\end{array}$ & $\begin{array}{l}\gamma_{\mathrm{lv}}^{\mathrm{p}} \\
\left(\mathrm{mJ} / \mathrm{m}^{2}\right)\end{array}$ \\
\hline Glycerol & 64.0 & 34 & 30 \\
Formamide & 58.3 & 32.3 & 26.0 \\
Ethene glycol & 48.3 & 29.3 & 19.0 \\
Polyglycol E-200 & 43.5 & 28.2 & 15.3 \\
Polyglycol 15-200 & 36.6 & 26.0 & 10.6 \\
\hline
\end{tabular}

profile photographs of the sessile drop being obtained every minute and a subsequently determined. After a test liquid drop of average volume $9 \mu \mathrm{l}$ attached and rested on the MgO-PSZ surface, the drops consistently reached an equilibrium state in around $6 \mathrm{~s}$. Thereafter they remained motionless and the magnitude of the contact angle changed little with time. On average, only $\pm 0.5^{\circ}$ deviation in the contact angle for each test liquid was observed during the 3 min measurement when time photographs were taken every minute, indicating that the shape of the drop was stable in its equilibrium state. As can be seen later from Fig. 5a, the difference between the contact angle values on the left-hand side and the right-hand side of the sessile drop is very small, just $0.6^{\circ}$, which generates $\pm 0.3^{\circ}$ deviation. In turn, the average total deviation for the contact angle measurement will be $\pm 0.8^{\circ}$.

\section{THE ANALYSIS OF $\mathrm{CO}_{2}$ LASER-INDUCED SOLIDIFICATION MICROSTRUCTURE ON THE MgO-PSZ}

The major effects of varying the thermal conditions on solidification microstructure are well known according to the theory of constitutional supercooling at low solidification rates and morphological stability theory at high solidification rates [32]. The extent of the zone of constitutional supercooling depends upon the operative solidification parameters, i.e. the solidification rate $R$ and thermal gradient $G$. Increasing the gradient-rate ratio $G / R$ causes a progressive change in the solidification characteristics, ranging from fully dendritic to cellular dendritic to cellular and finally to planar front 
growth. When the threshold of planar interface stability is exceeded a cellular interface is formed but, before any such cell structure is formed, several different stages have to be undergone [33]. When the degree of constitutional supercooling is small, i.e. $G / R$ is slightly less than that required for stability, the interface develops small irregularities; however, no definite structure is present. Increasing the degree of constitutional supercooling leads to the formation of fine elongated cells at the interface. On further increasing the degree of constitutional supercooling, the capped-hexagonal formation becomes the stable interface shape. Finally, when marked constitutional supercooling exists, the cellular shape is developed. At even larger supercooling $(G / R$ becomes even smaller), a transient from the cellular into cellular dendritic interface will occur [34].

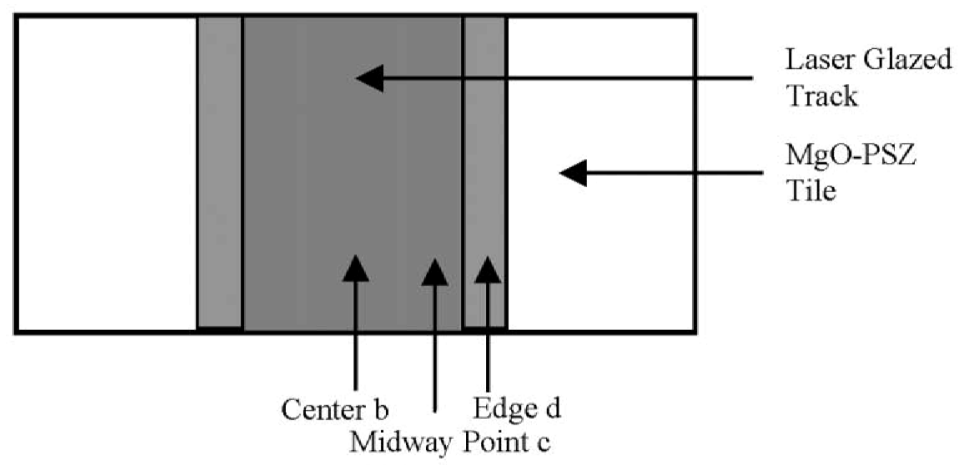

(a)

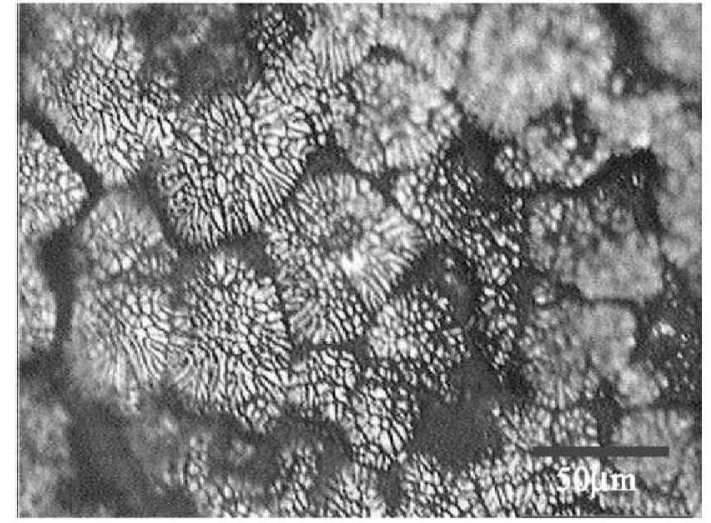

(b-1)

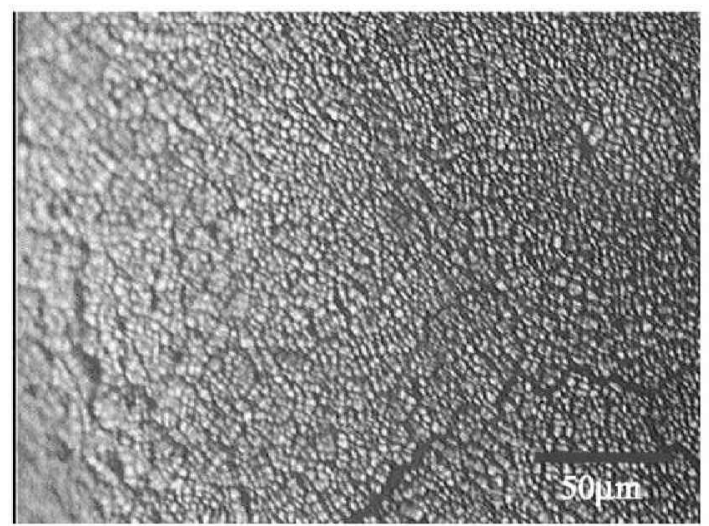

(c)

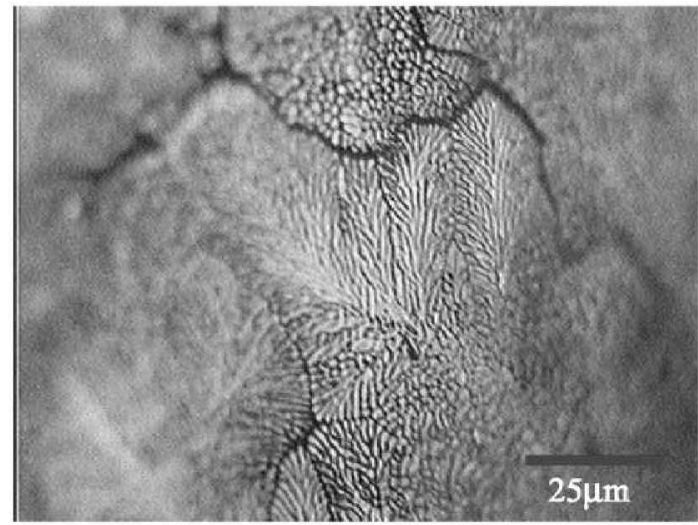

(b-2)

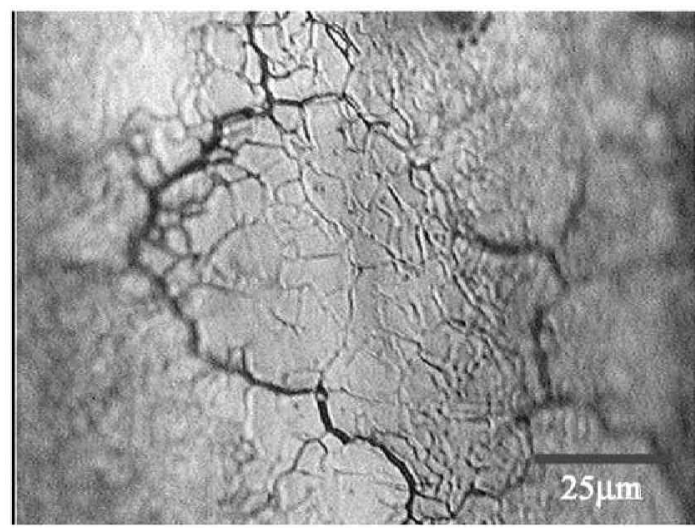

(d)

Fig. 2 Examination of the microstructure produced in the laser track: (a) schematic depiction of the area of the laser track analysed; (b)-(d) surface optical images of the microstructures (b-1), (b-2) at the centre, (c) at the midway point and (d) at the edge of the laser track (with a power density of $2.5 \mathrm{~kW} / \mathrm{cm}^{2}$ and a traverse speed of $2000 \mathrm{~mm} / \mathrm{min}$ ) 


\subsection{Solidification microstructure analysis}

Variations in the $\mathrm{CO}_{2}$ operating parameters (power density and traverse speed) were seen to effect significantly the microstructure obtained within the lasertreated areas on the MgO-PSZ surface. The surface microstructures were examined using optical microscopy. All microstructural features observed from the surface view were evaluated without metallographic polishing or etching. High heat input from a laser beam to melt a localized area on the surface sample can achieve high cooling rates; the cooling rate will be different from the centre to the edge of sample and cause different microstructures. Therefore, the microstructures obtained in different regions of the laser track may explain the effect of laser-induced solidification microstructure.

\subsection{Microstructures induced by a relatively high power density}

Figure 2a depicts schematically the regions analysed optically. One laser track was treated with a relatively high power density of $2.5 \mathrm{~kW} / \mathrm{cm}^{2}$ under a traverse speed of $2000 \mathrm{~mm} / \mathrm{min}$. As can be seen, different solidified microstructures were observed in the different regions, in the centre (Figs 2b-1 and b-2), at the midway point (Fig. 2c) and at the edge (Fig. 2d) of the $\mathrm{CO}_{2}$-laser-treated track on the MgO-PSZ.

The structures described as 'coral' and a few dendritic structures were found in the centre of the track, while a cellular structure was observed at the midway point of the track and a hexagonal structure appeared at the edge. According to constitutional supercooling theory, such a progressive change in the solidification characteristics within the same track, ranging from dendritic $\rightarrow$ cellular $\rightarrow$ hexagonal structure, indicates the different degrees of constitutional supercooling extending from the centre $\rightarrow$ the midway point $\rightarrow$ the edge of the $\mathrm{CO}_{2}$ laser-treated track on the MgO-PSZ surface.

In the centre of the track, a few dendritic structures shown in Fig. 2b-2 appeared, indicating that the ratio $G / R$ is small enough to form dendritic structures. Since the cooling rate is very high in the centre, secondary arms of the dendrites can be either completely absent or very short. Hence, a microcrystalline structure may be formed and these spherical cells may coalesce to form the 'coral' structure shown in Fig. 2b-1, in which the perimetric cells of the coalescence grow in accord with the dendritic pattern due to the relative slow scanning speed. On the other hand, the reason for the fine-grain structures may be that cellular dentriditic arms may have a slightly higher solute content than the outer portions of the arms. Hence, the melting point here would be lower, and the thermal fluctuations would tend to cause melting just at this location. In any case, the roots of the dendrite arms are often smaller in diameter than the exterior portions and, even if melting in response to a thermal fluctuation were uniform, it would result in separation of the arm from the main stalk. When the arm that is separated is then carried away into slightly supercooled liquids, a new crystal is formed without a new nucleation event.

In the laser solidification process, convection flow in the melt pool provides an applicable mechanism, not just for breaking off the arms of dendrites but also for dissipating superheat in the liquid so that the transported arm can grow. However, strong turbulent convection has the added effect of bringing heat pulses to the interface. These heat pulses accelerate the melting off of dendritic arms [35]. Therefore, some fine-grain cellular structures as shown in the left-hand part of Fig. 2c at the midway point on the MgO-PSZ, which show the undulating current, could come from the melted-off arms since a strong convection flow exists in the melt pool. The other cellular structures, shown in the right hand part of Fig. 2c at the midway point on the surface of the $\mathrm{MgO}-\mathrm{PSZ}$, could be the cells induced from direct solidification under supercooling.

At the edge, the $G / R$ ratio at the interface is just slightly less than that required for stability; i.e. the degree of constitutional supercooling is small. Consequently, the hexagonal structure shown in Fig. 2d can be easily formed and becomes a stable interface shape.

\subsection{Microstructures induced by a relatively low power density}

A typical example of the microstructure obtained with a relatively lower power density of $1.6 \mathrm{~kW} / \mathrm{cm}^{2}$ and traverse speed of $2000 \mathrm{~mm} / \mathrm{min}$ is shown in Fig. 3 . Again, it is evident that different solidified microstructures were observed in the different regions, at the centre (Fig. 3b), at the midway point (Figs 3c-1 and c-2) and at the edge (Fig. 3d) of the $\mathrm{CO}_{2}$-laser-treated track on the MgO-PSZ.

As can been seen from both Fig. 3b and Fig. 3d, the hexagonal microstructure appeared in the centre and edge of the laser-treated track, while the cellular structure is formed at the midway point shown in Figs 3c-1 and $\mathrm{c}-2$. Such solidification characteristics within the track indicate that the smallest gradient ratio is at the midway point with the maximum power density of the laser beam. At the centre and at the edge, the $G / R$ ratio is not high enough to produce a cellular structure and is just slightly less than that required for stability so that the hexagonal structure can be easily formed. The hexagonal structure seems flatter at the edge than at the centre, showing a more favourable gradient ratio for the planar structure. This indicates that the extent of constitutional supercooling is higher in the centre than at the edge, showing that the power density of laser beam at the centre is higher than at the edge. 


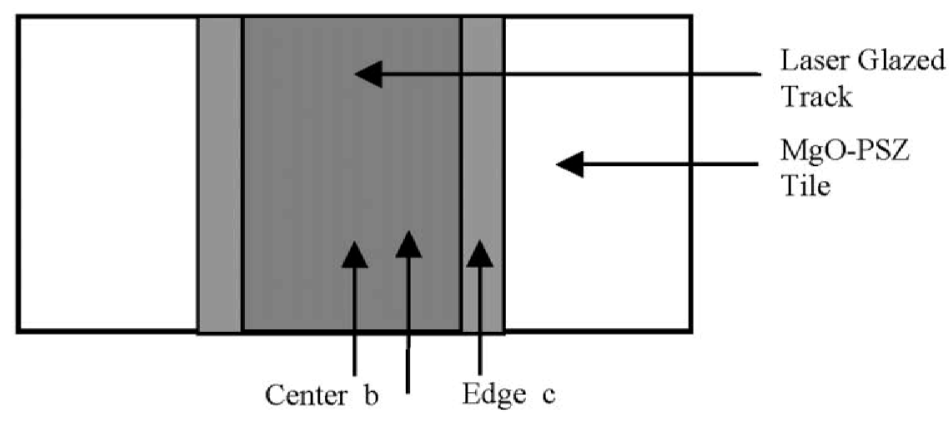

Midway Point d

(a)

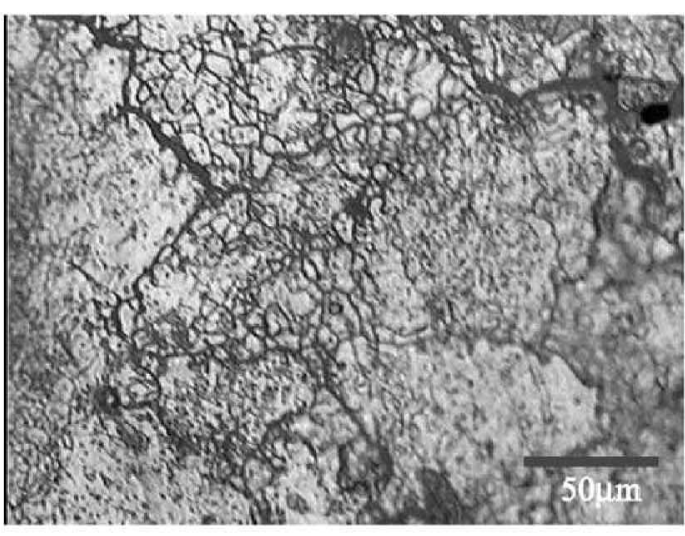

(b)

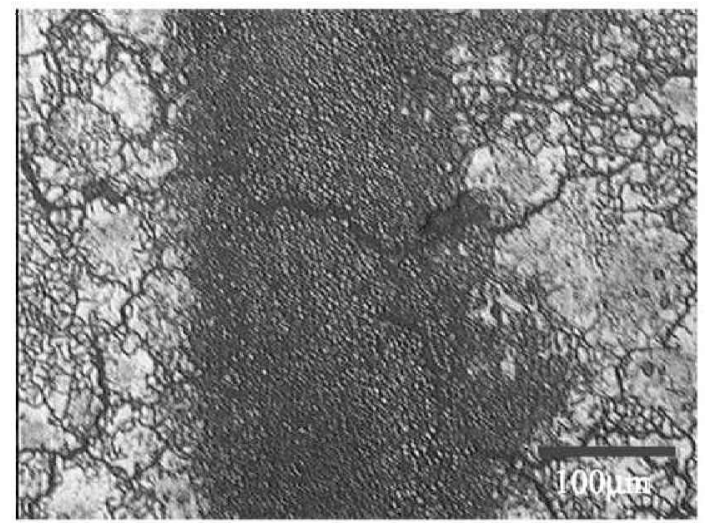

(c-2)

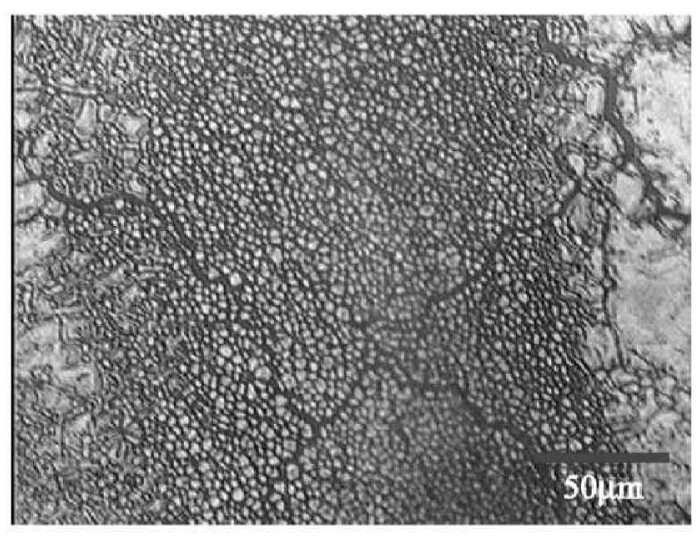

(c-1)

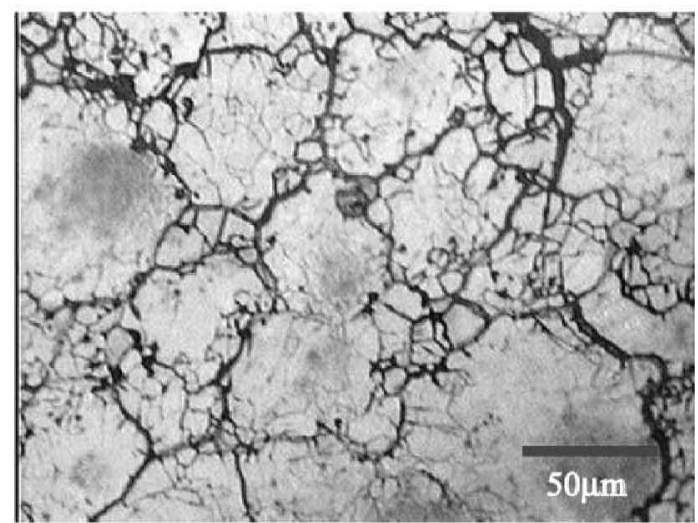

(d)

Fig. 3 Examination of the microstructure produced in the laser track: (a) schematic depiction of the area of the laser track analysed; (b)-(d) surface optical images of the microstructures (b) at the centre, (c-1), (c-2) at the midway point and (d) at the edge of the laser track (with a power density of $1.6 \mathrm{~kW} / \mathrm{cm}^{2}$ and a traverse speed of $2000 \mathrm{~mm} / \mathrm{min}$ )

\subsection{The effect of beam shape and the resulting temperature distribution}

The $\mathrm{CO}_{2}$ laser used in the experiment is a $\mathrm{TEM}_{01}$ multimode. As can be seen from Fig. 4, the power density distributions of the $\mathrm{CO}_{2}$ laser appear to be multi-mode. From Fig. 4a, it can see that the $\mathrm{CO}_{2}$ laser beam does not display a maximum peak in the middle of the beam; the peak is around the midpoint of the beam. Moreover, the small acrylic part at the centre has not been burnt out after $\mathrm{CO}_{2}$ laser treatment, indicating that the maximum power density is not situated at the centre but at the midpoint of the beam. The different $G / R$ ratios along the width of laser-treated track indicate that the laser beam is not a Gaussian mode beam, but a $\mathrm{TEM}_{01}$ mode beam. Based on the convective currents caused by a Gaussian beam profile [36, 37] and temperature distribution of the $\mathrm{TEM}_{01}$ beam profile, a schematic diagram of the convection currents is shown in Fig. 4c. From the schematic temperature distribution of the 


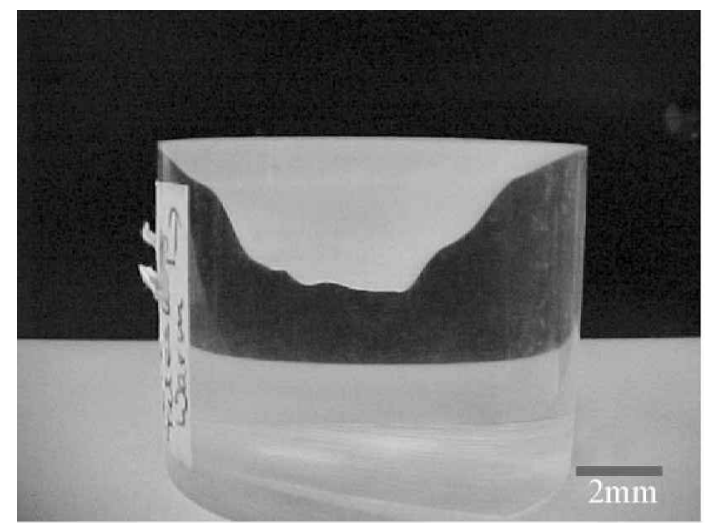

(a)

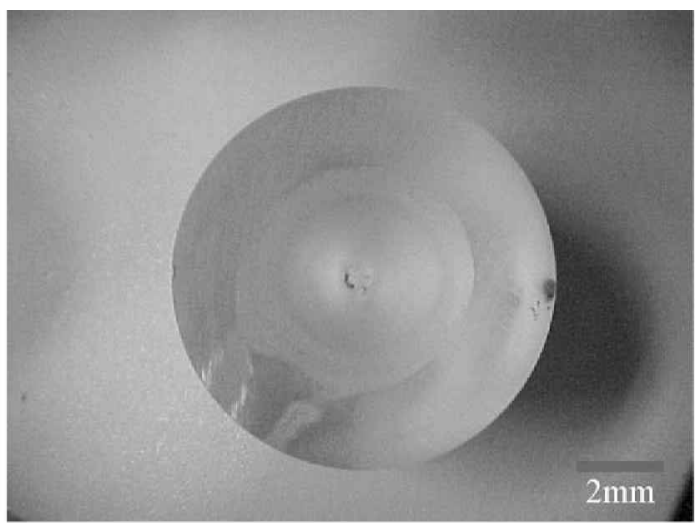

(b)

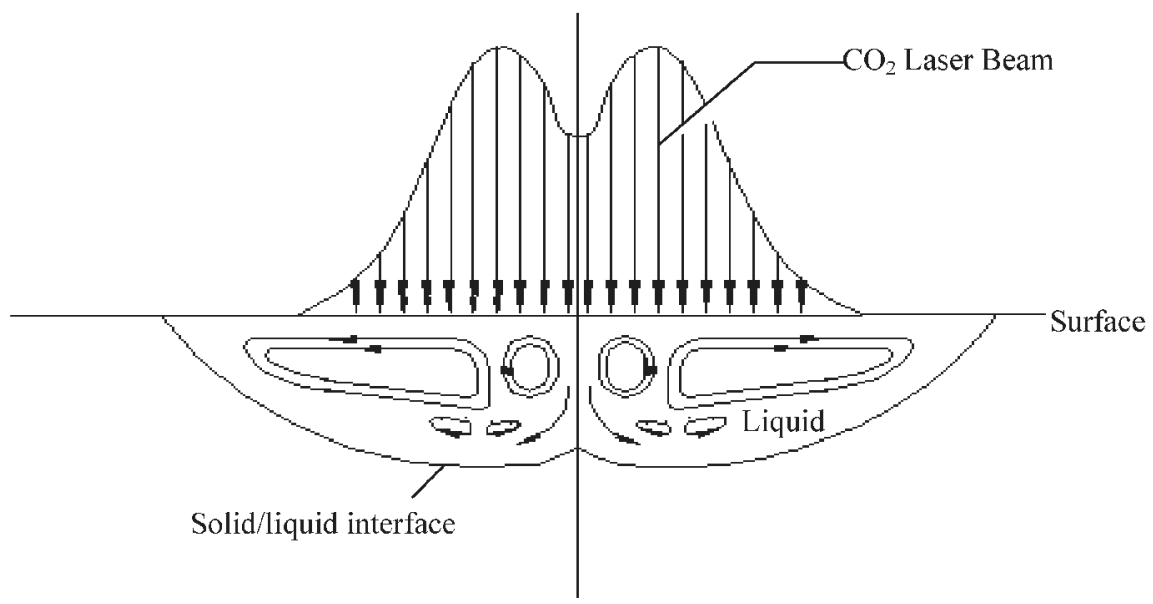

(c)

Fig. 4 Beam profile of the $\mathrm{TEM}_{01}$ multi-mode $\mathrm{CO}_{2}$ laser burnt on acrylic (a) from a parallel aspect and (b) from a vertical aspect; (c) schematic diagram of the convection currents generated within the laser melt pool

laser beam, it is shown that the highest temperature is not at the centre of the beam, but at the midway point near the centre. This is in accord with the result that the cellular structure formed at the midway point with the relatively low power density which has the lowest $G / R$ ratio with the highest temperature in the laser beam. Moreover, the temperature at the centre is higher than at the edge of the laser beam, so that $G / R$ at the centre is smaller than at the edge. This $G / R$ ratio distribution results in the formation of 'coral' and dendritic structure at the centre and hexagonal structure at the edge of the track with the relatively high power density. It also causes a less planar hexagonal structure in the centre than at the edge of the track with the relatively low power density.

Indeed, such findings have been reported by a number of workers conducting research into the laser treatment of various ceramics and alloys. Pei et al. [38] noted that both equiaxed and dendritic microstructures were obtained in different regions of the same laser-clad $\mathrm{ZrO}_{2}$ layer, concluding that the differences were related to different cooling rates in the various regions of the laser-clad $\mathrm{ZrO}_{2}$ layer. Liu [35] obtained similar results in laser-sealed $\mathrm{Y}_{2} \mathrm{O}_{3}-\mathrm{ZrO}_{2}$ and $\mathrm{MgO}-\mathrm{ZrO}_{2}$ ceramic coatings. Shih et al. [39] observed that, across a $\mathrm{YBa}_{2} \mathrm{Cu}_{3} \mathrm{O}_{x}$ and laser-clad track, different microstructures were found in different regions, and Shieh [40] made similar observations across a $\mathrm{SiO}_{2}-\mathrm{Al}_{2} \mathrm{O}_{3}$ laserclad track. Additionally, both noted not only that cellular and dendritic microstructures were visible but also that the microstructures were much finer on the edge of the clad track than at the centre. Such differences in microstructure type and size were ascribed to the various degrees of constitutional supercooling, which, according to McCallum et al. [41], are inherent in laser processes. In this study, different microstructures within one $\mathrm{CO}_{2}$ laser-treated track were observed and indicated the different stages of cell formation, due to the various 


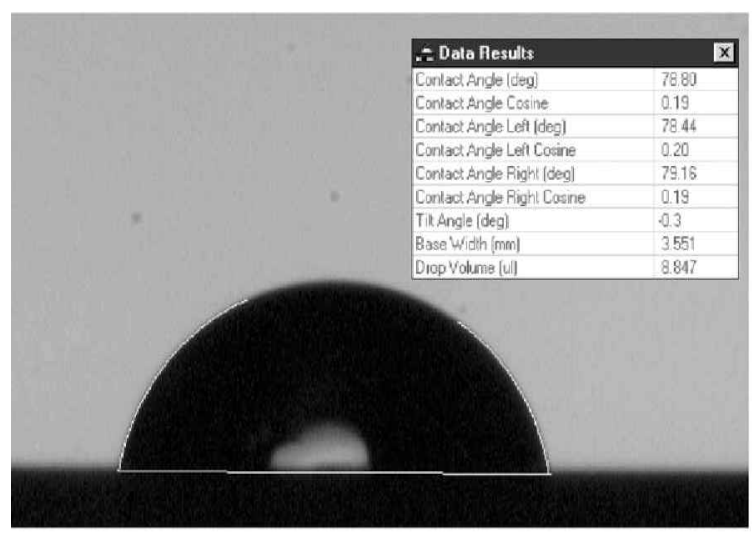

(a)

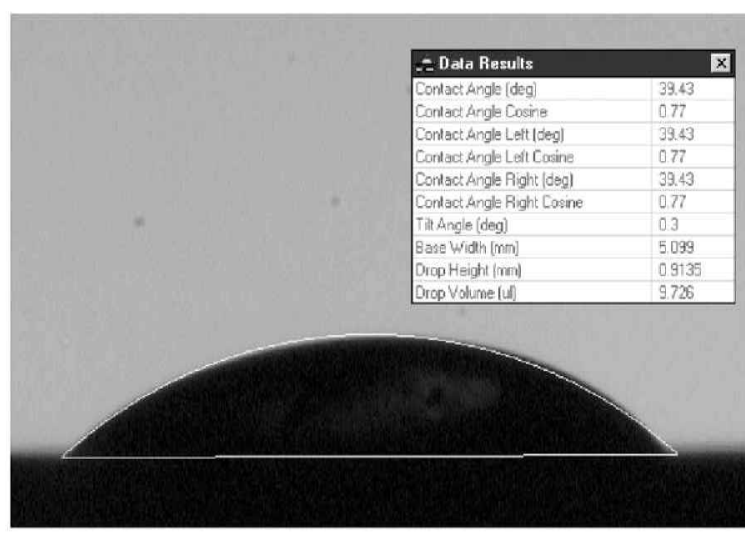

(b)

Fig. 5 Contact angles for glycerol on (a) the untreated surface and (b) the $\mathrm{CO}_{2}$-laser-treated surface of the $\mathrm{MgO}-\mathrm{PSZ}$ (with a power density of $1.6 \mathrm{~kW} / \mathrm{cm}^{2}$ and a traverse speed of $2000 \mathrm{~mm} / \mathrm{min}$ )

extents of constitutional supercooling with the different $G / R$ ratios across from the centre towards the edge of the track.

\section{THE EFFECTS OF $\mathrm{CO}_{2}$ LASER RADIATION ON THE WETTABILITY CHARACTERISTICS OF THE MgO-PSZ}

\subsection{Contact angle and wettability}

When a drop of liquid is in free space, it is drawn into a spherical shape by the tensile forces of its surface tension, which results from the attractive and repulsive forces that exist between the molecules of the liquid. When such a drop of liquid is brought into contact with a flat solid surface, the final shape taken by the drop (and thus whether it will wet the surface or not) depends upon the relative magnitudes of the molecular forces that exist within the liquid (cohesive) and between the liquid and the solid (adhesive) [42]. The contact angle is related to the solid-vapour surface energy $\gamma_{\mathrm{sv}}$, the liquid-vapour surface energy $\gamma_{\mathrm{lv}}$, and the solid-liquid interfacial energy $\gamma_{\mathrm{sl}}$, through the principal of virtual work expressed by the rearranged Young equation:

$$
\cos \theta=\frac{\gamma_{\mathrm{sv}} * \gamma_{\mathrm{sl}}}{\gamma_{\mathrm{lv}}}
$$

Clearly, to achieve wetting, $\gamma_{\mathrm{sv}}$ should be large, while $\gamma_{\mathrm{sl}}$ and $\gamma_{\mathrm{lv}}$ should be small. Hence liquids of a lower surface tension will always spread over a solid surface of higher surface tension in order to reduce the total free energy of the system [43]. This is because the molecular adhesion between solid and liquid is greater than the cohesion between the molecules of the liquid [42].

The adhesion intensity of a liquid to a solid surface is known as the work $W_{\text {ad }}$ of adhesion and is given by the Young-Dupre equation:

$$
W_{\text {ad }}=\gamma_{\mathrm{lv}}(1+\cos \theta)
$$

Optical micrographs of a sessile drop of glycerol placed on the surface of a MgO-PSZ sample before and after laser irradiation with the contact angle results are shown in Fig. 5. Additionally, as Table 2 shows, with all the control liquids used, the MgO-PSZ experienced a significant reduction in contact angle as a result of interaction with the $\mathrm{CO}_{2}$ laser beam.

Table 2 Mean values of contact angles formed between the untreated and laser-treated MgO-PSZ for various

\begin{tabular}{|c|c|c|c|c|c|c|}
\hline \multirow[b]{3}{*}{ Test liquid } & \multicolumn{6}{|c|}{ Contact angle $\theta$ (deg) } \\
\hline & \multirow[b]{2}{*}{ Untreated } & \multicolumn{5}{|c|}{$\mathrm{CO}_{2}$ laser treated at the following power densities } \\
\hline & & $0.5 \mathrm{~kW} / \mathrm{cm}^{2}$ & $0.9 \mathrm{~kW} / \mathrm{cm}^{2}$ & $1.6 \mathrm{~kW} / \mathrm{cm}^{2}$ & $1.9 \mathrm{~kW} / \mathrm{cm}^{2}$ & $2.5 \mathrm{~kW} / \mathrm{cm}^{2}$ \\
\hline Glycerol & 79 & 76 & 62 & 40 & 50 & 54 \\
\hline Formamide & 73 & 71 & 57 & 36 & 44 & 50 \\
\hline Ethene glycol & 61 & 60 & 48 & 29 & 38 & 41 \\
\hline Polyglycol E-200 & 53 & 51 & 40 & 26 & 33 & 36 \\
\hline Polyglycol 15-200 & 35 & 33 & 28 & 19 & 22 & 27 \\
\hline
\end{tabular}
power densities (traverse speed of $2000 \mathrm{~mm} / \mathrm{min}$ ) and the selected test liquids at $25^{\circ} \mathrm{C}$ 


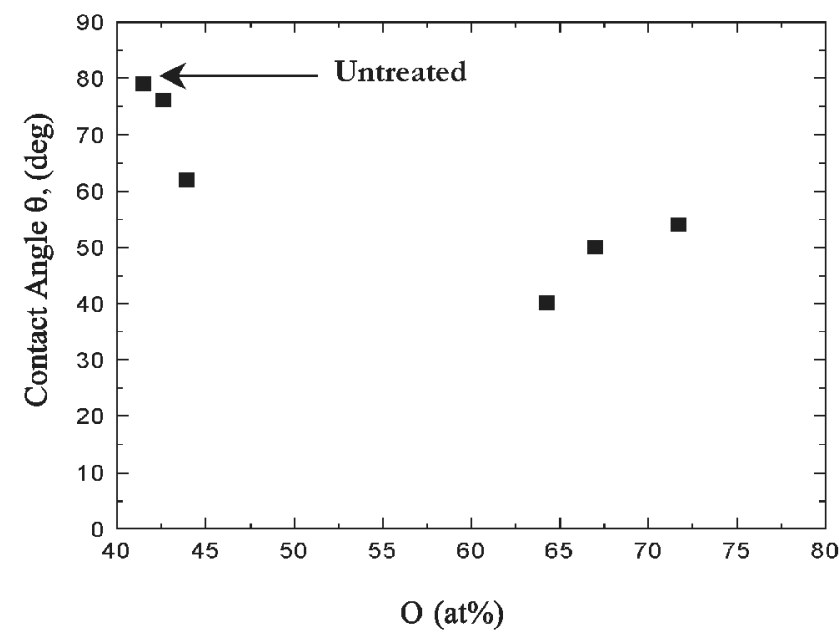

Fig. 6 Relationship between the glycerol contact angle and surface $\mathrm{O}$ content for the untreated and laser-treated $\mathrm{MgO}-\mathrm{PSZ}$ with various power densities

\subsection{The effect of surface oxygen content}

The observed increase in the wetting performance of the MgO-PSZ will have certainly been influenced by the increase in the $\mathrm{O}$ content of the MgO-PSZ surface as a result of the laser treatment, since this is known to increase the likelihood of wetting [44-47]. Wetting is governed by the first atomic layers of the surface of a material; thus, in order to determine accurately the content of the element $\mathrm{O}$ on the surface of the $\mathrm{MgO}$ PSZ, it was necessary to examine the surface using Xray photoemission spectroscopy.

It can be seen from Fig. 6 that an increase in the surface $\mathrm{O}$ content of the MgO-PSZ after interaction with the $\mathrm{CO}_{2}$ laser beam was observed. The values obtained showed that the $\mathrm{O}$ content increased from an initial value of $41.6-64.3$ at $\%$, while the contact angle of glycerol decreased from an initial value of 79 to $40^{\circ}$. As can be seen, an overall increase of some 22.7 at $\%$ in the amount of $\mathrm{O}$ on the $\mathrm{CO}_{2}$-laser-treated surface of this MgO-PSZ sample has occurred. This is believed to be due to the oxidation of the MgO-PSZ surface during melting and vitrification. When the $\mathrm{O}$ content increases to a value of 64.3 at $\%$, the contact angle decreased to its minimum value. This indicates that $\mathrm{O}$ enrichment of the $\mathrm{CO}_{2}$-laser-treated $\mathrm{MgO}$-PSZ surface is active in promoting wetting and adhesion, as well as bonding. This finding is similar to that of Song and Netravali $[\mathbf{4 6}, 4 \mathbf{4 7}$, who observed that the surface $\mathrm{O}$ content increased after laser treatment and, in turn, effected a reduction in the contact angle. However, when the $\mathrm{O}$ content is higher than 64.3 at $\%$, the contact angle increased despite the further increase in $\mathrm{O}$ content. This suggests that other mechanisms are active and more dominant and so cause the contact angle to increase.

\subsection{The effect of surface roughness}

It is important to consider also the influence of the substrate surface roughness on the wetting contact angle. Roughness grooves on a surface, which may contribute to the influence of contact angles, can be categorized as either radial or circular grooves. Any actual rough surface can be represented by a combination of these two cases [48]. In fact, two roughness parameters can be defined: the Wenzel [48] type, $D_{\mathrm{R}}$, and the Cassie-Baxter [49] type, $F_{\mathrm{R}}$. In the instance where wetting spreads radially, then the resulting radial contact angle $\theta_{\text {rad }}$ is related to the theoretical contact angle $[\mathbf{5 0}] \theta_{\text {th }}$ by

$$
\cos \theta_{\mathrm{rad}}=D_{\mathrm{R}}\left(1 * F_{\mathrm{R}}\right) \cos \theta_{\mathrm{th}} * F_{\mathrm{R}}
$$

According to Neumann [51], only if $F_{\mathrm{R}}$ is equal to zero, can a model similar to that for heterogeneous solid surfaces then be developed in order to account for surface irregularities and is given by the Wenzel equation

$$
r \cos \theta_{\text {ideal }}=\cos \theta_{\text {rough }}
$$

where $r$ is the roughness factor defined as the ratio of the real to apparent surface areas, and $\theta_{\text {ideal }}$ and $\theta_{\text {rough }}$ are contact angles for an ideal smooth surface and a rough surface respectively. It is important to note that Wenzel's treatment is only effective at the position of the wetting triple line [48]. Equation (4) shows that, if $r$ is large, i.e. the solid surface is rough, then $\cos \theta_{\text {rough }}$ is large and $\theta_{\text {rough }}$ decreases for $\theta<90^{\circ}$.

By varying the laser operating parameters it was possible to obtain a narrow range of surface roughness values. For experiment purposes only, the contact angles for glycerol in contact with the $\mathrm{CO}_{2}$-laser-treated $\mathrm{MgO}-\mathrm{PSZ}$ surface were obtained at various points across this narrow range of surface roughness values. As can be seen from Fig. 7, the surface of the untreated MgO-PSZ samples was very smooth, with an average $R_{\mathrm{a}}$ value of around $0.295 \mu \mathrm{m}$. After $\mathrm{CO}_{2}$ laser treatment it can be seen that the roughness of the MgO-PSZ surface increased. The results given in Fig. 7 reveal that $\mathrm{CO}_{2}$ laser treatment consistently brought about a rougher surface; $\theta$ was lower than that for the smoother untreated surface. This observation is according to equation (4) and the findings of other workers [52-55]; an increase in surface roughness ought to effect a decrease in $\theta$, when it is lower than $90^{\circ}$. Moreover, it must be noted that the experimental conditions in this study and in the previous work by others are very different. Whereas in the previous work only the surface roughness was altered, in this work the $\mathrm{CO}_{2}$ laser treatment effects changes in many other surface properties besides roughness. From Fig. 7, it is observed that, from an initial maximum $\theta$ of $79^{\circ}$ in the untreated state and a surface roughness of $0.295 \mu \mathrm{m}, \mathrm{CO}_{2}$ laser treatment results in a minimum $\theta$ of $40^{\circ}$ at a surface roughness of $0.717 \mu \mathrm{m}$. 


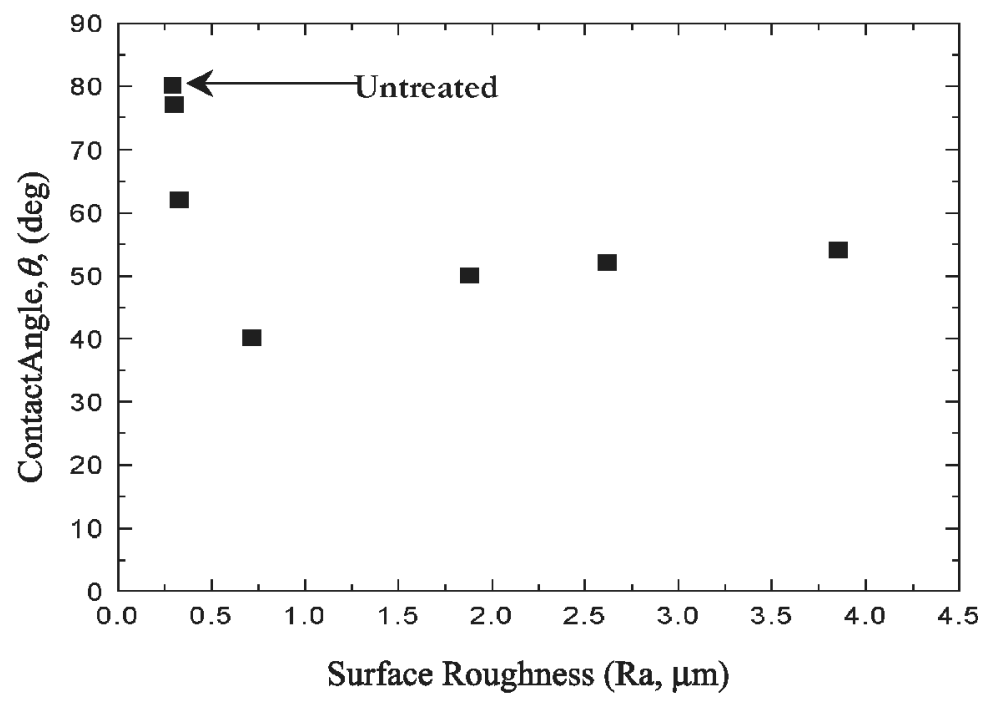

Fig. 7 Relationship between the glycerol contact angle and surface roughness for the untreated and lasertreated $\mathrm{MgO}-\mathrm{PSZ}$ with various power densities

However, it is also worth remarking that the increase in surface roughness of the MgO-PSZ obtained after laser treatment is very small, only about $0.4 \mu \mathrm{m}$, and is not proportional to the considerable reduction in the contact angle. Consequently, it is postulated that other factors such as changes in the surface energy and $\mathrm{O}$ content play a more predominant role than surface roughness in the significant decrease in contact angle for the $\mathrm{MgO}-\mathrm{PSZ}$ after $\mathrm{CO}_{2}$ laser treatment. This is enforced by the fact that, after the point with the minimum $\theta$, there is a relatively small increase from 40 to $54^{\circ}$ in $\theta$, despite the marked increase from 0.717 to $3.854 \mu \mathrm{m}$ in surface roughness.

\subsection{Effects of solidified microstructures and surface melting on contact angle}

In order to analyse the effects that the solidified structure of the MgO-PSZ surface has on the wettability performance of the MgO-PSZ, a series of wetting experiments

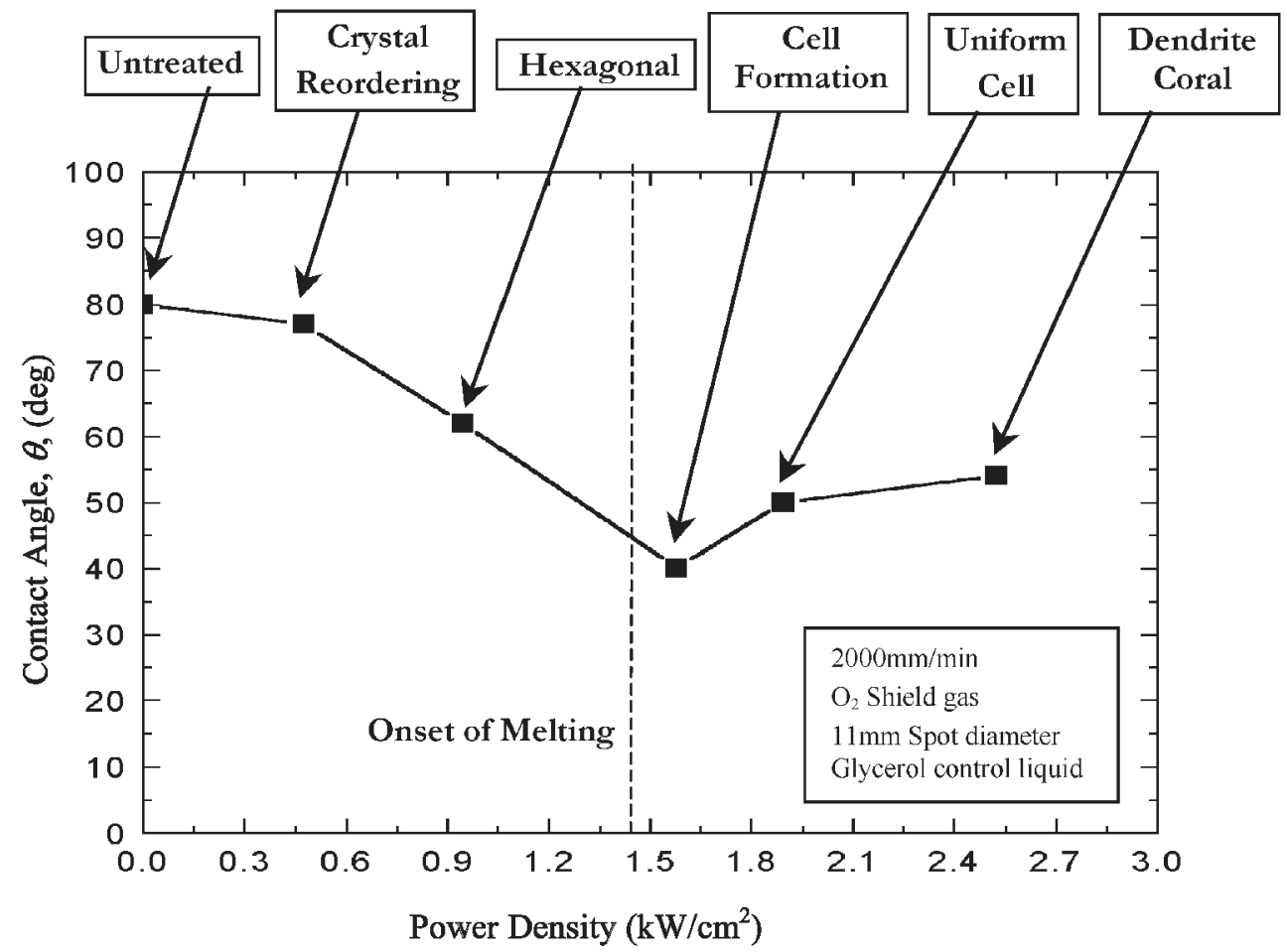

Fig. 8 Relationship between the contact angle on the untreated and $\mathrm{CO}_{2}$-laser-treated $\mathrm{MgO}-\mathrm{PSZ}$ and power density and solidified structure 
using only glycerol were conducted to determine the contact angle for a range of laser power densities. In this way, it was possible to obtain different solidified microstructure on the surface of the MgO-PSZ. In order to simplify the analysis, the structure was defined according to the main structure on the MgO-PSZ surface after $\mathrm{CO}_{2}$ laser treatment, as shown in Fig. 8. It can be seen from Fig. 8 that the microstructure on the surface of the $\mathrm{CO}_{2}$-laser-treated $\mathrm{MgO}$-PSZ is shown to have a significant effect on the contact angle. The mere reordering of crystals that occurs at power densities below around $0.5 \mathrm{~kW} / \mathrm{cm}^{2}$ appears to have only a slight effect on the contact angle, reducing it from 79 to $76^{\circ}$. At around $0.9 \mathrm{~kW} / \mathrm{cm}^{2}$, the contact angle decreases significantly from 77 to $62^{\circ}$, with the hexagonal structure on the MgO-PSZ surface. With a further increase in power density to around $1.6 \mathrm{~kW} / \mathrm{cm}^{2}$, the contact angle decreases sharply from 62 to $40^{\circ}$, with some crystalline cell structures beginning to form in the treated track. One reason for this sharp reduction in the contact angle at this point may be that melting is initiated with this power density, signifying that this is an essential prerequisite in order for significant reductions in the contact angle to be realized. After this point an increase in the contact angle from 40 to $50^{\circ}$ occurs corresponding to the point of uniform cell structure formation; then from 50 to $54^{\circ}$, dendrites and coral structure occurred. Indeed, work conducted by Zhang et al. [56] found that significant improvements in the bond strength of a $\mathrm{Si}_{3} \mathrm{~N}_{4}$ ceramic could be realized only when excimer laser treatment of a structural alloy steel (SAE 4340) resulted in surface melting. Similarly, Lawrence and Li [57] observed a sharp reduction in the contact angle at the point of melting onset of amalgamated oxide compound grout (AOCG) after HPDL treatment and a small but discernible increase in the contact angle with the generation of a rougher surface at higher power levels.

In general, the laser radiation induces the microstructural change and consequently causes a reduction in the contact angle on the MgO-PSZ surface. The contact angle begins to decrease significantly when the cellular structure forms on the surface. The onset of melting and cell formation creates a sharp decrease in the contact angle.

\subsection{Surface energy of the MgO-PSZ and dispersive or polar character}

\subsubsection{Surface energy of the $\mathrm{MgO}-\mathrm{PSZ}$}

The intermolecular attraction which is responsible for surface energy $\gamma$ results from a variety of intermolecular forces whose contribution to the total surface energy is additive [58]. The majority of these forces are functions of the particular chemical nature of a certain material, and as such the total surface energy consists of $\gamma^{\mathrm{p}}$ (polar or non-dispersive interaction) and $\gamma^{\mathrm{d}}$ (dispersive component, since van der Waals forces are present in all systems regardless of their chemical nature). Therefore, the surface energy of any system can be described by [59]

$$
\gamma=\gamma^{\mathrm{d}}+\gamma^{\mathrm{p}}
$$

Similarly, $W_{\text {ad }}$ can be expressed as the sum of the different intermolecular forces that act at the interface [60]:

$$
W_{\mathrm{ad}}=W_{\mathrm{ad}}^{\mathrm{d}}+W_{\mathrm{ad}}^{\mathrm{p}}=2\left(\gamma_{\mathrm{sv}}^{\mathrm{d}} \gamma_{\mathrm{lv}}^{\mathrm{d}}\right)^{1 / 2}+2\left(\gamma_{\mathrm{sv}}^{\mathrm{p}} \gamma_{\mathrm{lv}}^{\mathrm{p}}\right)^{1 / 2}
$$

However, by equating equation (6) to equation (2), the contact angle for solid-liquid systems where both dispersion forces and polar forces are present can be related to the surface energies of the respective liquid and solid by

$$
\cos \theta=\frac{2\left(\gamma_{\mathrm{sv}}^{\mathrm{d}} \gamma_{\mathrm{lv}}^{\mathrm{d}}\right)^{1 / 2}+2\left(\gamma_{\mathrm{sv}}^{\mathrm{p}} \gamma_{\mathrm{lv}}^{\mathrm{p}}\right)^{1 / 2}}{\gamma_{\mathrm{lv}}} * 1
$$

By plotting the graph of $\cos \theta$ against $\left(\gamma_{\mathrm{lv}}^{\mathrm{d}}\right)^{1 / 2} / \gamma_{\mathrm{lv}}$ according to equation (7), it is possible to estimate adequately the dispersive component of the MgO-PSZ surface energy, $\gamma_{\mathrm{sv}}^{\mathrm{d}}$. Thus, according to Fowkes [59], the value of $\gamma_{\mathrm{sv}}^{\mathrm{d}}$ is estimated from the gradient [equal to $2\left(\gamma_{\mathrm{sv}}^{\mathrm{d}}\right)^{1 / 2}$ ] of the line which connects the origin $(\cos \theta=* 1)$ with the intercept point of the straight line $[\cos \theta$ against $\left.\left(\gamma_{\mathrm{lv}}^{\mathrm{d}}\right)^{1 / 2} / \gamma_{\mathrm{lv}}\right]$ correlating the data point with the abscissa at $\cos \theta=1$. Figure 9 shows the best-fit plot of $\cos \theta$ against $\left(\gamma_{\mathrm{lv}}^{\mathrm{d}}\right)^{1 / 2} / \gamma_{\mathrm{lv}}$ according to equation (7) for the untreated and laser-treated MgO-PSZ-experimental control liquid system. From Fig. 9 the values of $\gamma_{\mathrm{sv}}^{\mathrm{d}}$ for the untreated and the $\mathrm{CO}_{2}$-laser-treated $\mathrm{MgO}$-PSZ were calculated as 42.7 and $48.2 \mathrm{~mJ} / \mathrm{m}^{2}$ respectively. Comparing the ordinate intercept points of the untreated and laser-treated MgO-PSZ-liquid systems, it can be seen clearly from Fig. 9 that, for the untreated $\mathrm{MgO}$ PSZ-liquid systems, the best-fit straight line intercepts the ordinate closer to the origin. This indicates that, in principle, dispersion forces act mainly at the $\mathrm{MgO}$ PSZ-liquid interfaces, resulting in poor adhesion $[\mathbf{5 9}, \mathbf{6 1}]$. In contrast, Fig. 9 shows that the best-fit straight line for the laser-treated MgO-PSZ-liquid systems intercepts the ordinate considerably higher above the origin. This is indicative of the action of polar forces across the interface, in addition to dispersion forces; hence improved wettability and adhesion is promoted [51, 53]. Additionally, since neither of the best-fit straight lines intercepts below the origin, then it can be assumed that no equilibrium film pressure of adsorbed vapour on the $\mathrm{MgO}-\mathrm{PSZ}$ surface (untreated and laser treated) occurred $[59,61]$.

The value of the polar component of the MgO-PSZ surface energy $\gamma_{\mathrm{sv}}^{\mathrm{p}}$ cannot be determined directly from Fig. 9. This is because the intercept of the straight line [cos $\theta$ against $\left.\left(\gamma_{\mathrm{lv}}^{\mathrm{d}}\right)^{1 / 2} / \gamma_{\mathrm{lv}}\right]$ is at $2\left(\gamma_{\mathrm{sv}}^{\mathrm{p}} \gamma_{\mathrm{lv}}^{\mathrm{p}}\right)^{1 / 2} / \gamma_{\mathrm{lv}}$ and thus only refers to individual control liquids and not to the 


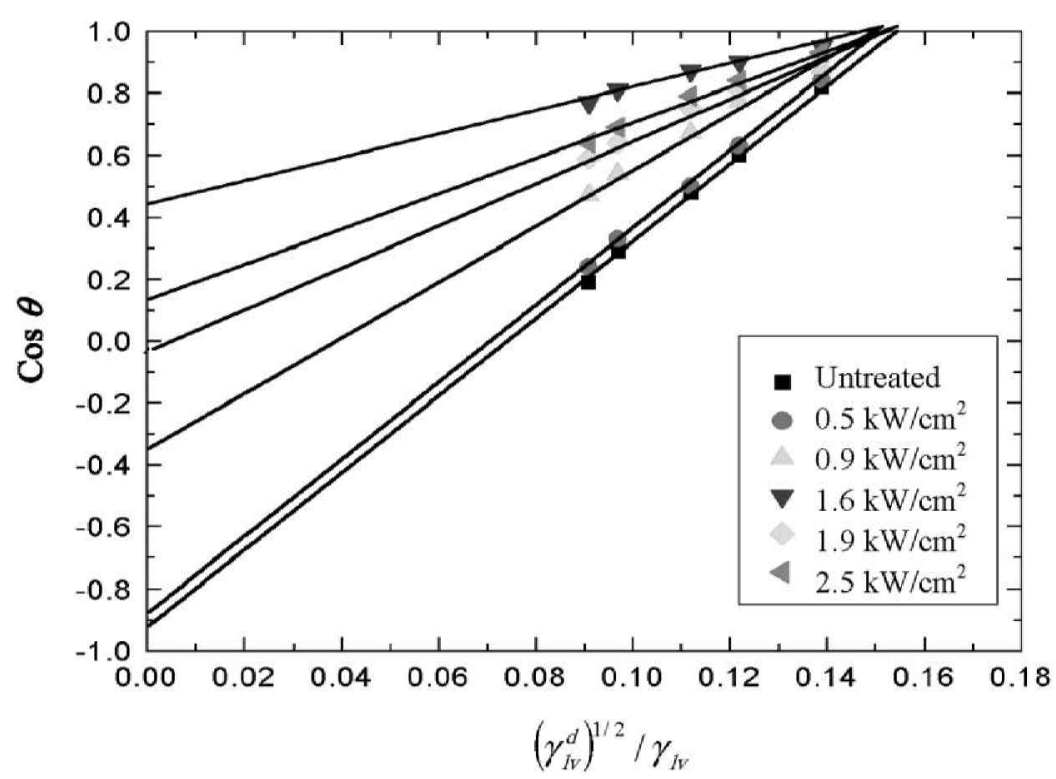

Fig. 9 Plot of $\cos \theta$ against $\left(\gamma_{\mathrm{lv}}^{\mathrm{d}}\right)^{1 / 2} / \gamma_{\mathrm{lv}}$ for the MgO-PSZ in contact with the wetting test control liquids, before and after $\mathrm{CO}_{2}$ laser treatment of various parameters

control liquid system as a whole. However, it has been established that the entire amount of the surface energies due to dispersion forces either of the solids or of the liquids are active in the wettability performance $[\mathbf{5 9}, \mathbf{6 2}]$. As such, it is possible to calculate the dispersive component of the work of adhesion, $W_{\text {ad }}^{\mathrm{d}}$, by using only the relevant part of equation (6); thus

$$
W_{\mathrm{ad}}^{\mathrm{d}}=2\left(\gamma_{\mathrm{sv}}^{\mathrm{d}} \gamma_{\mathrm{lv}}^{\mathrm{d}}\right)^{1 / 2}
$$

Table 3 shows the values of $W_{\text {ad }}$ calculated using equation (2) and the values of $W_{\mathrm{ad}}^{\mathrm{d}}$ calculated using equation (8) for both the untreated and the $\mathrm{CO}_{2}$-laser-treated MgO-PSZ. The results reveal that for each particular control liquid in contact with both the untreated and the $\mathrm{CO}_{2}$-laser-treated MgO-PSZ, from the plots of $W_{\mathrm{ad}}$ against $W_{\text {ad }}^{\text {d }}$ [29], $W_{\text {ad }}$ can be correlated with $W_{\text {ad }}^{\text {d }}$ by the line relationship

$$
W_{\mathrm{ad}}=a W_{\mathrm{ad}}^{\mathrm{d}}+b
$$

Also, for the control test liquids used, a linear relationship between the dispersive and polar components of the control test liquid surface energies was deduced which satisfied

$$
\left(\gamma_{\mathrm{lv}}^{\mathrm{p}}\right)^{1 / 2}=2.9\left(\gamma_{\mathrm{lv}}^{\mathrm{d}}\right)^{1 / 2} * 11.14
$$

By introducing equation (9) into equation (6) and rearranging, then

$$
W_{\mathrm{ad}}^{\mathrm{p}}=(a * 1) W_{\mathrm{ad}}^{\mathrm{d}}+b
$$

By introducing equation (10) into equation (6) and differentiating with respect to $\left(\gamma_{\mathrm{lv}}^{\mathrm{d}}\right)^{1 / 2}$, considering that $\left(\gamma_{\mathrm{sv}}^{\mathrm{d}}\right)^{1 / 2}$ and $\left(\gamma_{\mathrm{lv}}^{\mathrm{p}}\right)^{1 / 2}$ are constant, then the following can be derived:

$$
\left(\gamma_{\mathrm{sv}}^{\mathrm{p}}\right)^{1 / 2}=\frac{\left(\gamma_{\mathrm{sv}}^{\mathrm{d}}\right)^{1 / 2}(a * 1)}{2.9}
$$

From a plot of equation (11), $a$ can be determined for the untreated and $\mathrm{CO}_{2}$-laser-treated MgO-PSZ (2.41 and 4.25 respectively). Since $\gamma_{\mathrm{sv}}^{\mathrm{d}}$ has already been determined

\begin{tabular}{|c|c|c|c|c|c|c|c|c|c|c|c|}
\hline $\begin{array}{l}\text { Power } \\
\text { density } \\
\left(\mathrm{kW} / \mathrm{cm}^{2}\right)\end{array}$ & $a$ & \multicolumn{5}{|c|}{ Work $W_{\text {ad }}$ of adhesion for the following test liquids* } & \multicolumn{5}{|c|}{ Dispersive work $W_{\mathrm{ad}}^{\mathrm{d}}$ of adhesion for the following test liquids" } \\
\hline 0.5 & 2.37 & 79.4 & 77.5 & 72.5 & 70.9 & 67.3 & 77.2 & 75.2 & 71.6 & 70.3 & 67.5 \\
\hline 0.9 & 3.03 & 92.8 & 89.8 & 80.7 & 77.0 & 68.8 & 77.7 & 75.7 & 72.1 & 70.7 & 67.9 \\
\hline 1.6 & 4.25 & 113.3 & 105.5 & 90.3 & 82.7 & 71.4 & 80.9 & 78.8 & 75.1 & 73.7 & 70.8 \\
\hline 1.9 & 3.42 & 105.0 & 98.5 & 86.5 & 80.0 & 70.6 & 80.5 & 78.4 & 74.7 & 73.3 & 70.4 \\
\hline
\end{tabular}
for the untreated and laser-treated MgO-PSZ from Fig. 9 , then it is possible to calculate $\gamma_{\mathrm{sv}}^{\mathrm{p}}$ for untreated and

Table 3 Values of $W_{\text {ad }}$ and $W_{\text {ad }}^{\mathrm{d}}$ for the test liquids and determined for the constant $a$ from the plots of $W_{\text {ad }}$ against for the untreated (UT) and $\mathrm{CO}_{2}$-laser-treated $\mathrm{MgO}$-PSZ of various parameters

*Glyc, glycerol; Form, formamide; Ethene, ethane glycol; P1, polyglycol E-200; P2, polyglycol 15-200. 
Table 4 Determined surface energy values for the MgO-PSZ before and after laser treatment of various power densities (traverse speed of $2000 \mathrm{~mm} / \mathrm{min}$ )

$\mathrm{CO}_{2}$ laser treated at the following laser densities

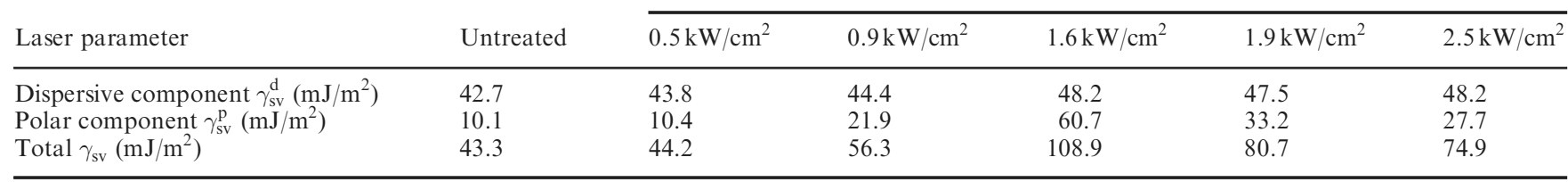

$\mathrm{CO}_{2}$-laser-treated $\mathrm{MgO}-\mathrm{PSZ}$ using equation (12) directly. Table 4 gives the values determined for $\gamma_{\mathrm{sv}}^{\mathrm{d}}$ and $\gamma_{\mathrm{sv}}^{\mathrm{p}}$ for both the untreated and the $\mathrm{CO}_{2}$-laser-treated MgO-PSZ.

As can be seen from Table 4, $\mathrm{CO}_{2}$ laser treatment of the surface of the MgO-PSZ leads to an overall increase in the total surface energy $\gamma_{\mathrm{sv}}$, from 52.8 to $108.9 \mathrm{~mJ} / \mathrm{m}^{2}$ while, more importantly, also significantly increasing the polar component of the surface energy $\gamma_{\mathrm{sv}}^{\mathrm{p}}$, from 10.1 to $60.7 \mathrm{~mJ} / \mathrm{m}^{2}$. These increases (in particular the increase in $\left.\gamma_{\mathrm{sv}}^{\mathrm{p}}\right)$ have a positive effect upon the action of wetting and adhesion [51], since primarily both dispersion and polar forces are active to a greater extent $[59,61]$. The changes in the surface energy of the MgO-PSZ after laser treatment are thought to be due to the fact that $\mathrm{CO}_{2}$ laser treatment of the surface of the $\mathrm{MgO}-\mathrm{PSZ}$ results in partial vitrification of the surface, a transition that is known to effect an increase in $\gamma_{\mathrm{sv}}^{\mathrm{p}}$ [62], and thus an improvement in the wettability characteristics and an increase in the adhesion at the interface in contact with the control liquids. This conclusion is in strong agreement with the findings of Agathopoulos and Nikolopoulos [63], who from a wettability analysis of $\mathrm{SiO}_{2}-\mathrm{TiO}_{2}$ in various states, from fully crystalline through to completely vitrified, found that, as the crystallites in the material decreased, $\gamma_{\mathrm{sv}}^{\mathrm{p}}$ increased.

\subsubsection{Surface energy and laser parameters}

In order to find the relationship between the microstructure and surface energy of the MgO-PSZ, samples treated under different power densities were analysed. Similarly, it is possible to estimate reasonably accurately $\gamma_{\mathrm{sv}}^{\mathrm{d}}$ of the MgO-PSZ before and after $\mathrm{CO}_{2}$ laser treatment at various power densities. Figure 9 shows the best-fit plot of $\cos \theta$ against $\left(\gamma_{\mathrm{lv}}^{\mathrm{d}}\right)^{1 / 2} / \gamma_{\mathrm{lv}}$ for the untreated and $\mathrm{CO}_{2}$-laser-treated MgO-PSZ material-experimental control liquid system. A comparison of the ordinate intercept points of the untreated and $\mathrm{CO}_{2}$-laser-treated MgO-PSZ material-liquid systems, shown in Fig. 9, reveals that, for the material-liquid systems of the untreated and $\mathrm{CO}_{2}$-laser-treated $\mathrm{MgO}$-PSZ with $0.5 \mathrm{~kW} / \mathrm{cm}^{2}$ power density, the best-fit straight line intercepts the ordinate relatively close to the origin. On the other hand, Fig. 9 shows that the best-fit straight line for the MgO-PSZ material-liquid systems of the samples treated by a higher laser power density intercept the ordinate considerably higher above the origin. The highest intercept point is for the sample treated with a power density of $1.6 \mathrm{~kW} / \mathrm{cm}^{2}$ and a traverse speed of $2000 \mathrm{~mm} / \mathrm{min}$. This is significant since an interception of the ordinate well above the origin is indicative of the action of polar forces across the interface, in addition to dispersion forces; hence improved wettability and adhesion is promoted [59, 61]. Therefore, it suggests that the action of polar forces and wettability of the $\mathrm{CO}_{2}$-laser-treated $\mathrm{MgO}$-PSZ can be modified according to the power densities. According to the values of $\gamma_{\mathrm{sv}}^{\mathrm{d}}$, it is possible to calculate $\gamma_{\mathrm{sv}}^{\mathrm{p}}$ directly for the untreated and $\mathrm{CO}_{2}$-laser-treated $\mathrm{MgO}$-PSZ material using equation (12) with the appropriate values of the constant $a$ given in Table 3 . Table 4 gives the values determined for $\gamma_{\mathrm{sv}}^{\mathrm{d}}$ and $\gamma_{\mathrm{sv}}^{\mathrm{p}}$, as well as the total surface energy for both the untreated and the $\mathrm{CO}_{2}$-laser-treated MgO-PSZ.

As can be seen from Fig. 10, after $\mathrm{CO}_{2}$ laser treatment, $\gamma_{\mathrm{sv}}$ and $\gamma_{\mathrm{sv}}^{\mathrm{p}}$ increased depending on the microstructures obtained at different laser parameters. However, $\gamma_{\mathrm{sv}}^{\mathrm{d}}$ experiences only a very slight increase. For the sample treated with a relatively low power density, only mere crystal reordering appeared on the surface of the $\mathrm{MgO}$ PSZ, with little change in the surface energy being seen. When a hexagonal microstructure was generated on the surface of the MgO-PSZ, obvious increases in $\gamma_{\mathrm{sv}}$ and $\gamma_{\mathrm{sv}}^{\mathrm{p}}$ are observed (see Fig. 10). For the sample treated with a relatively medium power density, the cell formation on the MgO-PSZ surface corresponded to the maximum $\gamma_{\mathrm{sv}}$ and $\gamma_{\mathrm{sv}}^{\mathrm{p}}$. With increases in the power density and traverse speed, the uniform cell microstructure on the surface of the MgO-PSZ causes $\gamma_{\mathrm{sv}}$ and $\gamma_{\mathrm{sv}}^{\mathrm{p}}$ to decrease from the maximum value. When coral and dendritic microstructures appear on the surface of the $\mathrm{MgO}-\mathrm{PSZ}, \gamma_{\mathrm{sv}}$ and $\gamma_{\mathrm{sv}}^{\mathrm{p}}$ are further reduced from their maxima. A similar trend of modification according to the laser parameter for the MgO-PSZ is also observed for the adhesion $W_{\text {ad }}$ of glycerol shown in Fig. 11.

\subsection{Identification of the main factors active during modification of wettability characteristics}

In order to elucidate and give a greater understanding of the basic process phenomena and the numerous factors involved, this section discusses the predominant influential 


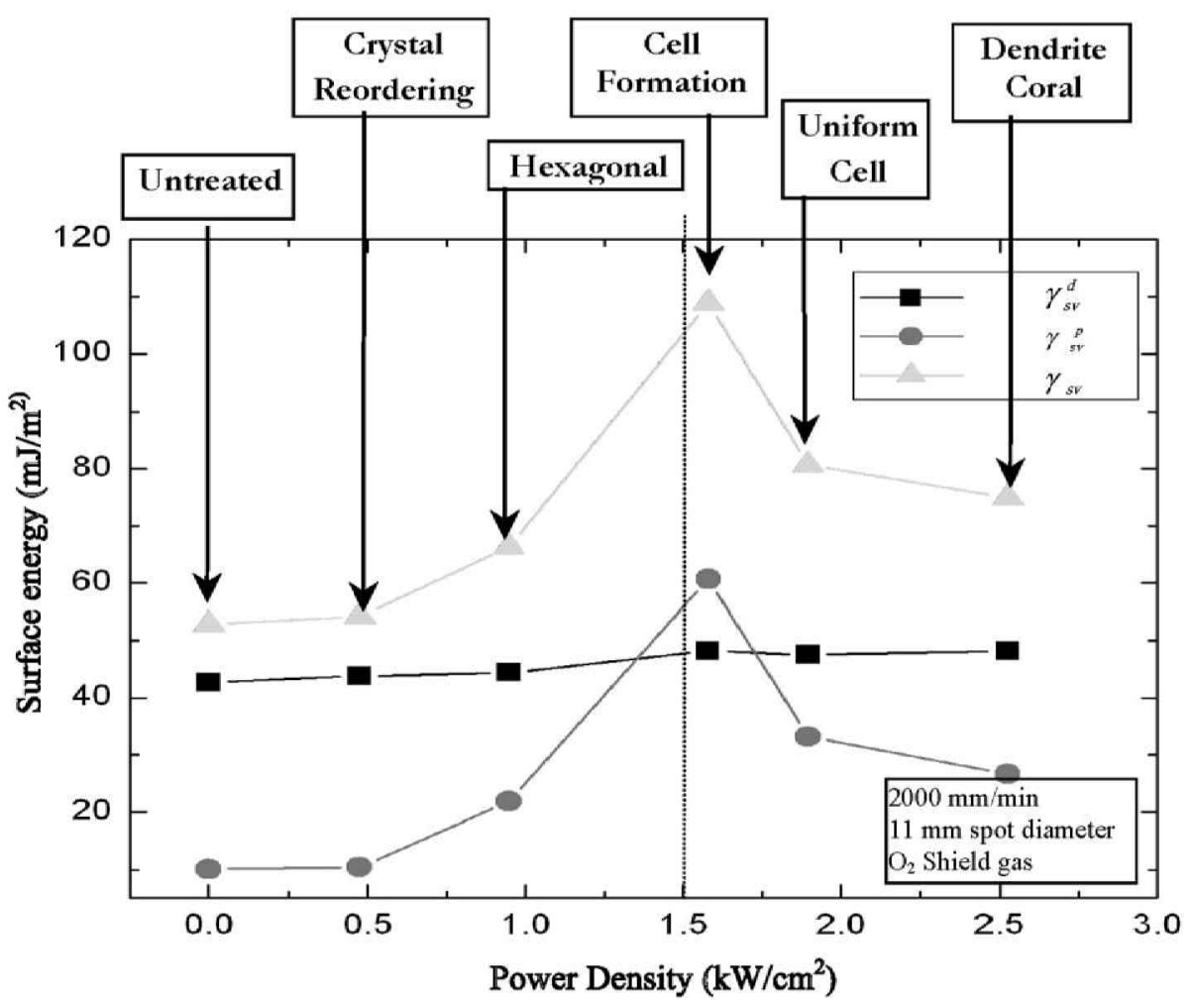

Fig. 10 Relationship between the surface energies $\gamma_{\mathrm{sv}}^{\mathrm{d}}, \gamma_{\mathrm{sv}}^{\mathrm{p}}$ and $\gamma_{\mathrm{sv}}$ of the $\mathrm{CO}_{2}$-laser-treated MgO-PSZ and power density

mechanisms, namely surface roughness, surface $\mathrm{O}$ content, surface microstructure and surface chemistry, and the individual effects thereof on the $\mathrm{CO}_{2}$-laser-modified wettability characteristics of the MgO-PSZ.

Lawrence [28] conducted work to isolate these influential factors, thereby allowing the magnitude of their influence to be determined. The analysis of HPDL radiation on selected metallic materials revealed that surface roughness was the primary influential factor governing changes in contact angle and hence the wettability characteristics of the mild steels, while the surface energy, by way of microstructural changes, was found to be by far the most predominant element governing the wetting characteristics of the $\mathrm{SiO}_{2}-\mathrm{Al}_{2} \mathrm{O}_{3}$-based ceramic. To a much lesser extent, the surface $\mathrm{O}$ content, by way of the process gas, was also seen to influence a change in the wettability characteristics of the $\mathrm{SiO}_{2}-$ $\mathrm{Al}_{2} \mathrm{O}_{3}$-based ceramic, while the surface roughness was

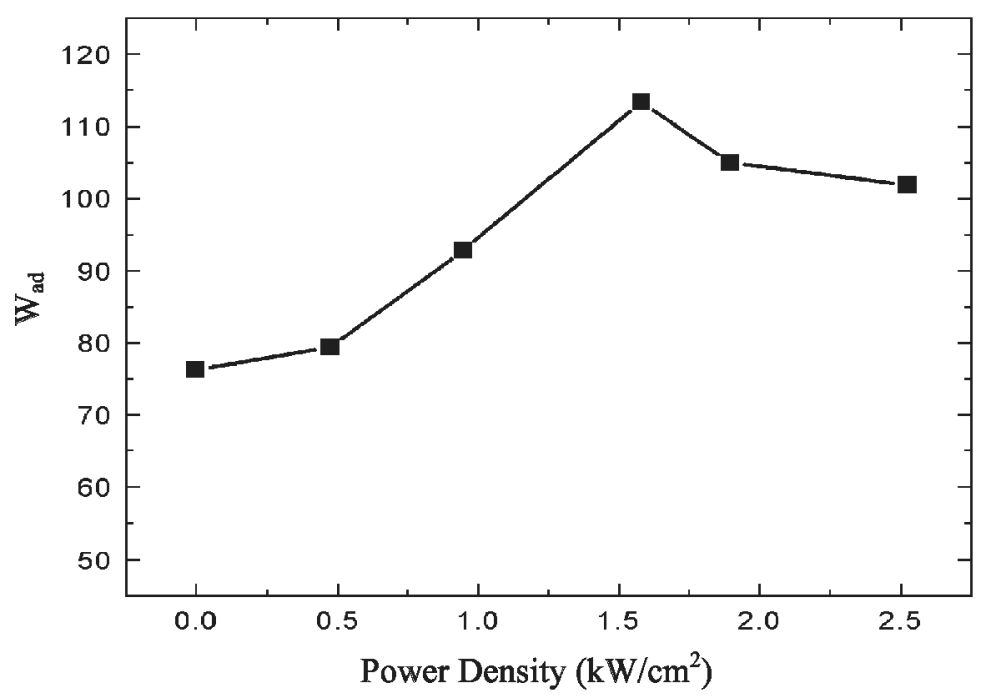

Fig. 11 Relationship between the work of adhesion of glycerol on $\mathrm{CO}_{2}$-laser-treated $\mathrm{MgO}$-PSZ and power density 
found to play a minor role in inducing changes in the wettability characteristics.

In order to investigate the influential factors on the wettability characteristics of the MgO-PSZ surface, the contact angles for glycerol were measured against the surface roughness, the surface $\mathrm{O}$ content, the microstructure and the polar component of surface energy.

In order to analyse the influential interrelationship between $\cos \theta$ and surface roughness specific to the $\mathrm{CO}_{2}$-laser-treated $\mathrm{MgO}-\mathrm{PSZ}$, the experimental results obtained are compared graphically as shown in Fig. 12. It is observed that even a slight increase in roughness of surface below $0.717 \mu \mathrm{m}$ causes $\cos \theta$ to increase in accordance with equation (4). After this point, $\cos \theta$ decreases despite a sharp increase in surface roughness, indicating that other factors influence the value of $\cos \theta$. Therefore, the rougher surface of the modified sample has a higher value of $\cos \theta$ than the smooth untreated sample, but the change in $\cos \theta$ is not proportional to the alteration in the surface roughness. It must be noted that in this work the $\mathrm{CO}_{2}$ laser treatment effects changes in many other surface properties besides roughness. It is believed that other mechanisms play a more predominant role in influencing the wettability characteristics of the $\mathrm{CO}_{2}$-laser-treated MgO-PSZ than the surface roughness.

Consequently, it is necessary to investigate the other factors known to influence wettability characteristics, namely the $\mathrm{O}$ content and the polar component of the surface energy. As can be seen from Fig. 12, $\cos \theta$ increased with corresponding increase in the surface $\mathrm{O}$ content when the value of the surface $\mathrm{O}$ content is lower than $63.4 \mathrm{at} \%$. This indicates that surface $\mathrm{O}$ content is certainly one of the factors influencing the wettability characteristics of the MgO-PSZ. This is in accord with the established theory for the relationship between the $\mathrm{O}$ content of materials and their wettability characteristics [44-47]. However, when the value of the surface $\mathrm{O}$ content is higher than 63.4 at \%, further increase in the surface $\mathrm{O}$ content does not cause a

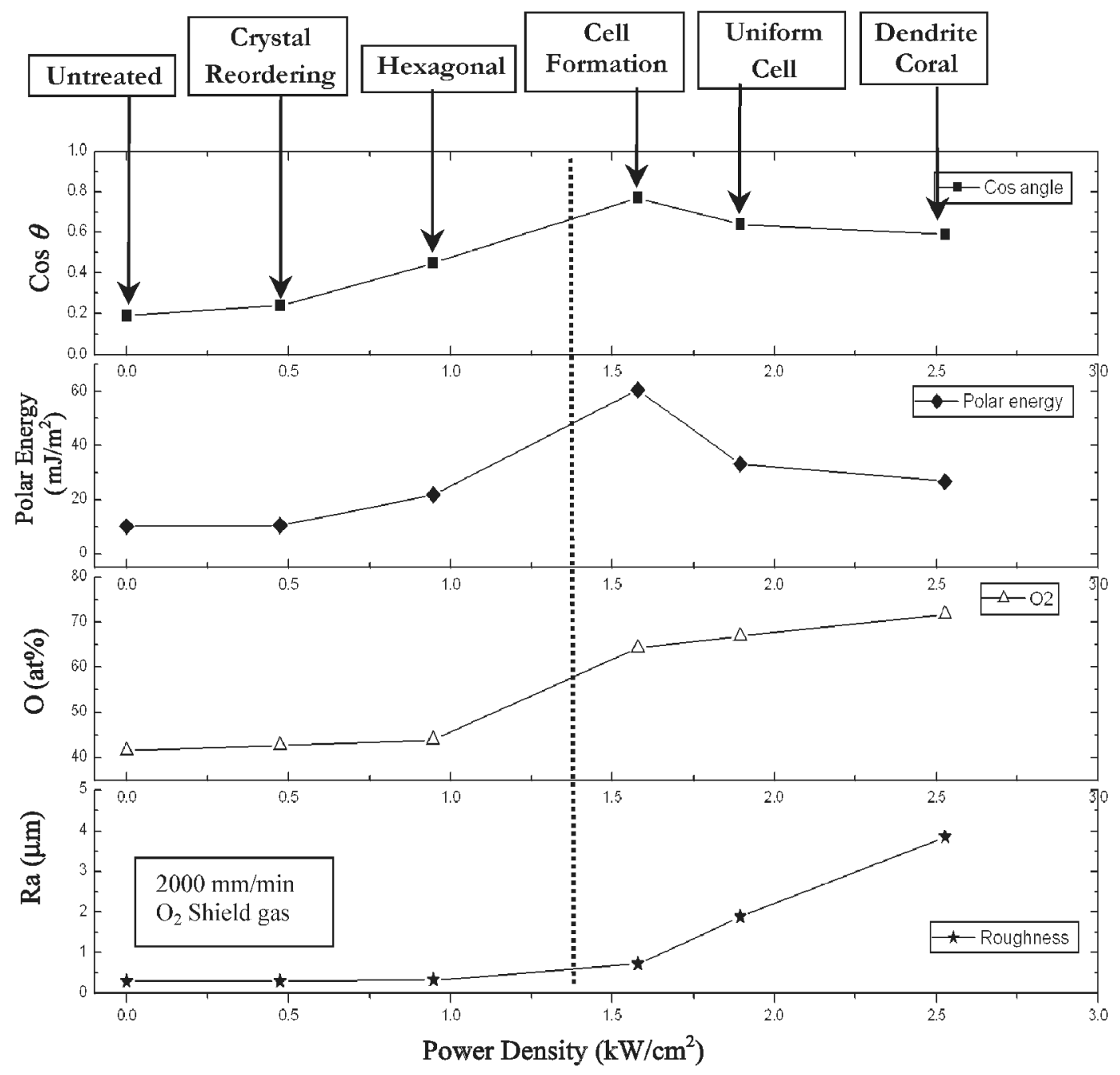

Fig. 12 Relationship between $\cos \theta$ for glycerol and the surface roughness, the surface O content, the polar component of surface energy and the microstructures of the untreated and $\mathrm{CO}_{2}$-laser-treated $\mathrm{MgO}-\mathrm{PSZ}$ surface 
higher value of $\cos \theta$. This suggests that the $\mathrm{O}$ content is not a major factor active in changing the wettability characteristics of the $\mathrm{MgO}-\mathrm{PSZ}$. A clear relationship between the value of $\cos \theta$ and the polar component of surface energy can be observed in Fig. 12, which reveals that an increase in $\gamma_{\mathrm{sv}}^{\mathrm{p}}$ will cause a rise in $\cos \theta$. Moreover, since a relationship was found between the surface microstructure and the surface energy of the MgO-PSZ previously, it is assumed that the surface energy and the surface microstructure are the chief influential factors on the wettability characteristics of the MgO-PSZ.

\section{CONCLUSIONS}

The results presented in this work are a clear indication that $\mathrm{CO}_{2}$ laser surface treatment brought about the microstructure change and the improvement in surface energy of the MgO-PSZ. The extent of this wettability characteristics modification was generated by manipulation of the laser operating parameters. The influential factors active in effecting the changes in the value of the wettability characteristics are identified as follows:

1. Surface solidification and melting. The $\mathrm{CO}_{2}$ laser treatment induced various solidified microstructures on the MgO-PSZ surface, causing different values of contact angle for the test liquids. It was found that a sharp reduction in contact angle was accompanied by the onset of melting and forming of crystal on the surface of the MgO-PSZ.

2. Increase in the polar component of the surface energy, $\gamma_{\mathrm{sv}}^{\mathrm{p}}$. This results from the melting and laser rapid solidification of the MgO-PSZ surface. The action force of $\gamma_{\mathrm{sv}}^{\mathrm{p}}$ and wettability of the MgO-PSZ increased after $\mathrm{CO}_{2}$ laser treatment.

3. Surface $O$ content. The increase in the surface $\mathrm{O}$ content of the $\mathrm{MgO}$-PSZ resulting from surface oxidation followed $\mathrm{CO}_{2}$ laser treatment was identified as further promoting the action of wetting, since an increase in surface $\mathrm{O}$ content inherently effects a decrease in the contact angle.

4. Surface energy. It is believed that surface energy, by way of microstructural changes, is by far the most predominant element governing the wetting characteristics of the MgO-PSZ. The surface $\mathrm{O}$ content is also seen to influence a change in the wettability characteristics of the MgO-PSZ, while the surface roughness is found to play a minor role in inducing changes in the wettability characteristics.

\section{ACKNOWLEDGEMENT}

The authors would like to express their gratitude to the Singapore Institute of Manufacturing Technology for allowing them to use their $\mathrm{CO}_{2}$ laser.

\section{REFERENCES}

1 Ohl, A. and Schroder, K. Plasma-induced chemical micropatterning for cell culturing applications: a brief review. Surf. Coatings Technol., 1999, 116-119, 820-830.

2 Kasemo, B. and Gold, J. Implant surfaces and interface processes. Adv. Dental Res., 1999, 13, 8-20.

3 Duncan, A. C., Weisbuch, F., Rouais, F., Lazare, S. and Baquey, Ch. Laser microfabricated model surfaces for controlled cell growth. Biosensors and Bioelectronics, 2002, 17, 413-426.

4 Ball, M. D., Downes, S., Scotchford, C. A., Antonov, E. N., Bagratashvili, V. N., Popov,V. K., Lo, W. J., Grant, D. M. and Howdle, S. M. Osteoblast growth on titanium foils coated with hydroxyapatite by pulsed laser ablation. Biomaterials, 2001, 22, 337-347.

5 D’Alessio, L., Ferro, D., Marotta, V., Santagata, A., Teghil, R. and Zaccagnino, M. Laser ablation and deposition of Bioglass ${ }^{\circledR}$ 45S5 thin films. Appl. Surf. Sci., 2001, 183, 10-17.

6 Alessio, L. D., Teghil, R., Zaccagnino, M., Zaccardo, I., Ferro, D. and Marotta, V. Pulsed laser ablation and deposition of bioactive glass as coating material for biomedical applications. Appl. Surf. Sci., 1999, 138-139, 527-532.

7 Serra, P. and Morenza, J. L. Fluence dependence of hydroxyapatite laser ablation plumes. Thin Solid Films, 1998, 335, 43-48.

8 Hontsu, S., Matsumoto, T., Ishii, J., Nakamori, M., Tabata, H. and Kawai, T. Electrical properties of hydroxyapatite thin films grown by pulsed laser deposition. Thin Solid Films, 1997, 295, 214-217.

9 Villermaux, F., Tabrizian, M., Yahia, L. H., Meunier, M. and Piron, D. L. Excimer laser treatment of NiTi shape memory alloy. Appl. Surf. Sci., 1997, 109-110, 62-66.

10 Yue, T. M., Yu, J. K. and Man, H. C. The effect of excimer laser surface treatment on pitting corrosion resistance of 316LS stainless steel. Surf. Coatings Technol., 2001, 137, 65-71.

11 Yue, T. M., Yu, J. K., Mei, Z. and Man, H. C. Excimer laser surface treatment of $\mathrm{Ti}-6 \mathrm{Al}-4 \mathrm{~V}$ alloy for corrosion resistance enhancement. Mater. Lett., 2002, 52, 206-212.

12 Cheang, P., Khor, K. A., Teoh, L. L. and Tam, S. C. Pulsed laser treatment of plasma-sprayed hydroxyapatite coatings. Biomaterials, 1996, 17, 1901-1904.

13 Mirzadeha, H., Katbabr, A. and Burford, P. $\mathrm{CO}_{2}$-laser graft copolymerization of Hema and NVP onto ethylene-propylene rubber (EPR) as biomaterial-(III). Radiat. Phys. Chem., 1995, 46, 859-862.

14 Mirzadeha, H., Katbabr, A., Khorasani, M. T., Burford, P., Gorgin, E. and Golestani, A. Cell attachment to laserinduced AAm- and HEMA-grafted ethylene-propylene rubber as biomaterial: in vivo study. Biomaterials, 1995, 168, 641-648

15 Lawrence, J. and $\mathbf{L i}, \mathbf{L}$. Modification of the wettability characteristics of polymethyl methacrylate (PMMA) by means of $\mathrm{CO}_{2}, \mathrm{Nd}$ :YAG, excimer and high power diode laser radiation. Mater. Sci. Engng, 2001, A303, 142-149.

16 Lawrence, J. and $\mathbf{L i}$, L. Carbon steel wettability characteristics enhancement for improved enamelling using a $1.2 \mathrm{~kW}$ high power diode laser. Optics Lasers Engng, 2000, 32, 353 365 . 
17 Lawrence, J. and Li, L. Wettability characteristics of carbon steel modified with $\mathrm{CO}_{2}, \mathrm{Nd}: \mathrm{YAG}$, excimer and high power diode lasers. Appl. Surf. Sci., 2000, 154-155, 664-669.

18 Heitz, J., Arenholz, E., Kefer, T., Bäuerle, D., Hibst, H. and Hagemeyer, A. Enhanced adhesion of metal films on PET after UV-laser treatment. Appl. Phys. A, 1992, 55, 391-392.

19 Watanabe, H. and Takata, T. Surface treatment of polyethylene films. Sen'-I Gakkaishi, 1993, 49, 616-623.

20 Andrew, J. E., Dyer, P. E., Forter, D. and Key, P. H. Direct etching of polymeric materials using a $\mathrm{XeCl}$ laser. Appl. Phys. Lett., 1983, 43, 717-718.

21 Watanabe, H. and Takata, T. Direct excimer laser etching of polymeric materials. J. Adhesion Sci. Technol., 1994, 6, $1425-1438$

22 Laurens, P., Sadras, B., Decobert, F., Arefiknonsari, F. and Amouroux, J. Enhancement of the adhesive bonding properties of PEEK by excimer laser treatment. Int. J. Adhesion Adhes., 1998, 18, 19-27.

23 Laurens, P., Ould Bouali, M., Meducin, F. and Sadras, B. Characterization of modifications of polymer surfaces after excimer laser treatments below the ablation threshold. Appl. Surf. Sci., 2000, 154-155, 211-216.

24 Heitz, J., Arenholz, E., Kefer, T., Bäuerle, D., Hibst, H. and Hagemeyer, A. Enhanced adhesion of metal films on PET after UV-laser treatment. Appl. Phys. A, 1992, 55, 391-392.

25 Henari, F. and Blau, W. Excimer laser surface treatment of metals for improved adhesion. Appl. Optics, 1995, 34, 581584.

26 Lawrence, J. and $\mathbf{L i}, \mathbf{L}$. Wettability characteristics of an $\mathrm{Al}_{2} \mathrm{O}_{3} / \mathrm{SIO}_{2}$ based ceramic modified with $\mathrm{CO}_{2}, \mathrm{Nd}$ :YAG, excimer and high power diode lasers. J. Phys. D: Appl. Phys., 1999, 32, 1075-1082.

27 Lawrence, L., Li, L. and Spencer, J. T. Diode laser modification of ceramic material surface properties for improved wettability and adhesion. Appl. Surf. Sci., 1999, 138-139, 388-393.

28 Lawrence, J. On the predominant mechanisms active during the high power diode laser modification of the wettability characteristics of an $\mathrm{SiO}_{2} / \mathrm{Al}_{2} \mathrm{O}_{3}$-based ceramic material. Proc. R. Soc. Lond. A, 2002, 2026, 2445-2463.

29 Hao, L. and Lawrence, J. $\mathrm{CO}_{2}$ laser modification of wettability characteristics of a magnesia partially stabilised zirconia (MgO-PSZ) bioceramic. J. Phys. D: Appl. Phys., 2003, 36(11), 1292-1299.

30 Hao, L. and Lawrence, J. Effects of $\mathrm{CO}_{2}$ laser radiation on the wettability characteristics and human skin fibroblast cell response of magnesia partially stabilised zirconia. J. Mater. Sci. Engng C, 2003, 23, 627-639.

31 Kinloch, A. J. Adhesion and Adhesives: Science and Technology, 1987, p. 30 (Chapman and Hall, London).

32 Esquivel, O., Mazumder, J., Bass, M. and Copely, S. M. Microstructural formation according to the theory of constitutional supercooling. In Rapid Solidification Processing, Principles and Technologies II (Eds R. Mehrabian, B. H. Kear and M. Cohen), 1980, pp. 150-173 (Claitor's Publishing Division, Baton Rouge, Louisiana).

33 Chadwick, G. A. Constitutional supercooling and microsegregation. In Fractional Solidification (Eds M. Zief and W. R. Wilcox), 1967, pp. 120-128 (Academic Press, New York).
34 Holmes, E. L., Rutter, J. W. and Winegard, W. C. Growth conditions for stability of a cellular solid-liquid interface. Can. J. Phys., 1957, 35, 1223-1227.

35 Liu, Z. Surface modification of materials using high power lasers and an arc image intensifier. PhD thesis, University of Liverpool, 1991.

36 Rivindram, K., Srinivasan, J. and Marathe, A. G. Finite element study on the role of convection in laser surface melting. Numer. Heat Transfer, 1994, 26, 601-618.

37 Morvan, D., Cipriani, F. D. and Bournot, P. Thermocapillary convection during laser surface melting. Int. J. Heat Mass Transfer, 1994, 37, 1973-1983.

38 Pei, Y. T., Ouyang, J. H. and Lei, T. C. Laser cladding of $\mathrm{ZrO}_{2}-(\mathrm{Ni}$ alloy) composite coating. Surf. Coatings Technol., 1996, 81, 131-135.

39 Shih, C. H. S., Molian, P. A., McCallum, R. W. and Balachandran, $\mathbf{U}$. Laser surface refinement of $\mathrm{YBa}_{2} \mathrm{Cu}_{3} \mathrm{O}_{x}$ superconductor. J. Mater. Sci., 1994, 29, 1629-1635.

40 Shieh, Y. N., Rawlings, R. D. and West, D. R. F. Laser processing of ceramics of the $\mathrm{SiO}_{2}-\mathrm{Al}_{2} \mathrm{O}_{3}$ system. J. Mater. Sci., 1994, 29, 5285-5292.

41 McCallum, R. W., Kramer, M. J. and Weir, S. T. Phase diagram effects in rapid thermal processing of $\mathrm{REBa}_{2} \mathrm{Cu}_{3} \mathrm{O}_{7 * \delta}$. IEEE Trans. Appl. Supercond., 1993, 3, 1147-1149.

42 Jaycock, M. J. and Parfitt, G. D. Chemistry of Interfaces, 1981 (John Wiley, Chichester, West Sussex).

43 Zisman, W. A. Contact angle, wettability and adhesion. Adv. Chem. Ser., 1964, 43, 1-51.

44 Ueki, M., Naka, M. and Okamoto, I. Wettability of transition metal oxide surfaces. J. Mater. Sci. Lett., 1986, 5, 1261-1262.

45 Li, J. G. Microscopic approach of adhesion and wetting of liquid metal on solid ionocovalent oxide surface. Rare Metals, 1993, 12, 84-96.

46 Song, Q. and Netravali, A. N. Excimer laser surface modification of ultro-high-strength polythene fibres for enhanced adhesion with epoxy resins. Part 1: effect of laser operating parameters. J. Adhesion Sci. Technol., 1998, 9, 957-982.

47 Song, Q. and Netravali, A. N. Excimer laser surface modification of ultro-high-strength polythene fibres for enhanced adhesion with epoxy resins. Part 2: effect of treatment environment. J. Adhesion Sci. Technol., 1998, 9, 983-998.

48 Wenzel, R. N. Resistance of solid surfaces to wetting by water. Ind. Engng Chem., 1936, 28, 988-994.

49 Cassie, A. B. D. and Baxter, S. Wettability of porous surfaces. Trans. Faraday Soc., 1944, 40, 546-551.

50 Zhou, X. B. and De Hosson, Th. M. J. Influence of surface roughness on the wetting angle. J. Mater. Res., 1995, 10, 1984-1992.

51 Neumann, A. W. Contact angles: thermodynamic status, measurement, interpretation and application. Adv. Colloid Interface Sci., 1974, 4, 105-192.

52 Chow, T. S. Wetting of rough surfaces. J. Phys.: Condensed Matter, 1998, 10, 445-451.

53 Marsh, J. A. and Cazabat, A. M. Dynamics of contact line depinning from a single defect. Phys. Rev. Lett., 1993, 71, 2433-2436.

54 Ertas, D. and Karder, M. Critical dynamics of contact line depinning. Phys. Rev. Lett., 1994, 49, 2532-2535.

55 Feng, A., McCoy, B. J., Munir, Z. A and Cagliostro, D. Wettability of transition metal oxide surfaces. Mater. Sci. Engng, 1998, A1-A2, 50-56. 
56 Zhang, X. M., Yue, T. M. and Man, H. C. Enhancement of ceramic to metal adhesive bonding by excimer laser surface treatment. Mater. Lett., 1997, 30, 327-332.

57 Lawrence, J. and Li, L. Laser Modification of the Wettability Characteristics of Engineering Materials, 2001 (Professional Engineering Publishing Limited, Bury St Edmunds and London).

58 Adam, N. K. and Elliott, G. E. P. The effects of high temperature variations on contact angle measurements of vitreous enamels. J. Chem. Soc., 1958, 18, 2206-2215.

59 Fowkes, F. M. Attractive forces at interface. Ind. Engng Chem., 1964, 56, 40-52.
60 Dann, J. R. Forces involved in the adhesive process. I: critical surface tensions of polymeric solids as determined with polar liquids. J. Colloid Interface Sci., 1970, 32, 302-320.

61 Chattoraj, D. K. and Birdi, K. S. Adsorption and the Gibbs Surface Excess, 1984 (Plenum, New York).

62 Good, R. J. and Girifalco, L. A. A theory for the estimation of surface and interfacial energies. III: estimation of surface energies of solids from contact angle data. J. Phys. Chem., 1960, 64, 561-565.

63 Agathopoulos, S. and Nikolopoulos, P. Wettability and interfacial interactions in bioceramic-body-liquid system. Biomed. Mater. Res., 1995, 29, 421-429. 
Copyright of Proceedings of the Institution of Mechanical Engineers -- Part B -Engineering Manufacture is the property of Professional Engineering Publishing and its content may not be copied or emailed to multiple sites or posted to a listserv without the copyright holder's express written permission. However, users may print, download, or email articles for individual use. 